NBER WORKING PAPER SERIES

\title{
UNINSURED IDIOSYNCRATIC INVESTMENT RISK AND AGGREGATE SAVING
}

\author{
George-Marios Angeletos
}

Working Paper 11180

http://www.nber.org/papers/w11180

\author{
NATIONAL BUREAU OF ECONOMIC RESEARCH \\ 1050 Massachusetts Avenue \\ Cambridge, MA 02138 \\ March 2005
}

\begin{abstract}
An earier version of the paper was entitled "Idiosyncratic Investment Risk in the Neoclassical Growth Model"; the current title paraphrases that of Aiyagari's (1994) seminal paper. For helpful feedback and discussions, I am thankful to Daron Acemoglu, Olivier Blanchard, Francisco Buera, Ricardo Caballero, Laurent Calvet, Tom Krebs, and Iván Werning. I also thank seminar participants at MIT, UCLA, Columbia, Brown, the Minneapolis Fed, and the 2003 SED meeting. The views expressed herein are those of the author(s) and do not necessarily reflect the views of the National Bureau of Economic Research.
\end{abstract}

(C) 2005 by George-Marios Angeletos. All rights reserved. Short sections of text, not to exceed two paragraphs, may be quoted without explicit permission provided that full credit, including $\odot$ notice, is given to the source. 
Uninsured Idiosyncratic Investment Risk and Aggregate Saving

George-Marios Angeletos

NBER Working Paper No. 11180

March 2005

JEL No. D52, E13, E32, G11, O16, O41

\begin{abstract}
This paper augments the neoclassical growth model to study the macroeconomic effects of idiosyncratic investment risk. The general equilibrium is solved in closed form under standard assumptions for preferences and technologies. A simple condition is identified for incomplete markets to result in both a lower interest rate and a lower capital stock in the steady state: the elasticity of intertemporal substitution must be higher than the income share of capital. For plausible calibrations of the model, the reduction in the steady-state levels of aggregate savings and income relative to complete markets is quantitatively significant. Finally, cyclical variation in private investment risks is shown to amplify the transitional dynamics.
\end{abstract}

George-Marios Angeletos

Department of Economics

MIT

50 Memorial Drive, E51-251

Cambridge, MA 02142

and NBER

angelet@mit.edu 


\section{Introduction}

Following Bewley (1977), Aiyagari (1994) and Krusell and Smith (1998), an extensive literature has examined the macroeconomic implications of idiosyncratic labor-income risk, but has largely neglected idiosyncratic risks in private production and capital returns. ${ }^{1}$ In contrast, the typical investor in the US economy - and presumably even more so in less developed economies - appears to be exposed to large idiosyncratic risks in capital returns: privately-held businesses account for almost half of aggregate production, employment, and capital in the United States. ${ }^{2}$

This paper provides a tractable benchmark for examining the macroeconomic effects of idiosyncratic investment risk within the context of the neoclassical growth model. It then makes a first attempt at quantifying these effects.

I introduce uninsured idiosyncratic investment risk in an otherwise standard neoclassical growth economy. Households supply labor in a competitive labor market, but invest capital in privatelyheld firms. Firms, in turn, operate a neoclassical technology subject to firm-specific productivity shocks, which translate to idiosyncratic capital-income risk for the households. Households have isoelastic (CRRA/CEIS) preferences. They can freely borrow and lend in a riskless bond, but they can not diversify their capital-income risk.

A key property of the neoclassical growth model is not affected by the introduction of idiosyncratic investment risk: capital accumulation exhibits diminishing returns at the aggregate level, but linear returns at the individual level. For given sequence of prices, the households' decision problem is homothetic and the optimal decision rules are therefore linear in individual wealth. As a result, the aggregate dynamics do not depend on the wealth distribution, which avoids the "curse of dimensionality" and permits closed-form solution of the general-equilibrium recursion.

I next focus on the steady state. Incomplete markets introduce a risk premium on private investment, which reduces the demand for capital. This effect would unambiguously lead to a lower capital stock if the interest rate were exogenous. However, the interest rate is lower than the discount rate, because of the Aiyagari-like precautionary-savings effect. The lower interest rate in turn tends to stimulate investment. As a result, the general-equilibrium effect on capital accumulation is ambiguous in general. Nevertheless, a simple necessary and sufficient condition is identified for the risk premium to dominate the reduction in the interest rate when risks are small: incomplete markets lead to a lower capital stock if and only if the elasticity of intertemporal substitution exceeds a threshold which is lower than the income share of capital.

\footnotetext{
${ }^{1}$ For a review of the Bewley literature and references, see Ljungqvist and Sargent (2000, chs 13-14).

${ }^{2}$ Quadrini (1999), Gentry and Hubbard (2000) and Carrol (2001) document the importance of private equity for savings and wealth concentration. Moskowitz and Vissing-Jørgensen (2002) further document the dramatic lack of diversification in the private-equity holdings and the overall portfolio of private investors, and the high cross-section variation in the return to private equity. Finally, idiosyncratic investment risks need not be limited to private equity if individuals do not diversify their public-equity holdings, housing, and other forms of savings.
} 
Since the income share of capital is much lower than most empirical estimates of the elasticity of intertemporal substitution, a negative effect on aggregate savings and income appears to be the most likely scenario. Indeed, for plausible calibrations of the model, steady-state level of income under incomplete markets is about $10 \%$ less than what under complete markets.

These findings contrast sharply with the over-accumulation of capital predicted by Bewley-type models where idiosyncratic risk is only in endowment or labor income (e.g., Aiyagari, 1994). They also qualify the insights delivered by $A K$ models such as Obstfeld (1994) and Jones, Manuelli, and Stacchetti (2000). In these models, investment risk is known to have a positive effect on savings and growth when the elasticity of intertemporal substitution is less than one, but this is only because the income share of capital is one. ${ }^{3}$

In the benchmark model, the entire capital stock is held in private firms. I next extend the model so that a fraction of aggregate savings is in "public equity", where idiosyncratic risks are pooled. Because the low risk-free rate stimulates investment in public equity, the negative impact of incomplete markets on aggregate savings is significantly mitigated. Nevertheless, incomplete markets now also reduce aggregate total factor productivity by shifting resources away from the more risky but also more productive private equity. As a result, the impact on aggregate output remains quantitatively important.

In overall, although the lack of good estimates of the level of idiosyncratic investment risk does not permit a precise calibration of the model, large quantitative effects on savings and income are consistent with small idiosyncratic risks and low excess returns in private equity: when I calibrate the model so that the risk premium on private equity is as low as $1 \%$, the reduction in the steadystate level of income remains in the order of $10 \%$.

Turning to the transitional dynamics, I show that cyclical variation in private risk premia may lead to amplification. Cyclical variation in private premia in turn originates in two separate sources: cyclical variation in the level of uninsured investment risk; and the equilibrium interaction of wealth and risk taking, namely the fact that, under incomplete markets, individual investment depends on the present value of future income, which in turn depends on current aggregate investment. This interaction indeed introduces a novel macroeconomic complementarity, a short of "Keynesian accelerator".

In plausible calibrations, the complementarity alone turns out to have a rather modest effect, because it is offset by the endogenous reaction of interest rates. In contrast, cyclical variation in the level of idiosyncratic risk is found to have strong effects: a "flight to quality" towards less risky public equity during recessions generates endogenous cyclicality in the Solow residual and thereby amplifies the transitional dynamics.

\footnotetext{
${ }^{3}$ The risk is idiosyncratic in Obstfeld (1994), whereas it is aggregate in Jones et. al. (2000). This makes little difference, however, with a linear $A K$ technology.
} 
Related Literature. The paper contributes to the Bewley literature (e.g., Aiyagari, 1994; Huggett, 1993, 1997; Krusell and Smith, 1998) by examining the macroeconomic impact of idiosyncratic investment risks. These risks are shown to have very different steady-state and business-cycle implications than labor-income risks.

In this respect, the paper complements my work in Angeletos and Calvet (2003, 2004), which also considered entrepreneurial risks, but assumed constant absolute risk aversion, thus killing altogether the effect of wealth on precautionary savings, risk taking, and investment. Here, instead, I allow wealth effects by assuming standard CRRA/CEIS preferences. I also introduce a competitive labor market and a public-equity sector.

Unlike the Bewley literature, ${ }^{4}$ however, the paper does contribute to the analysis of the wealth distribution. It also takes the lack of insurance as exogenous. Meh and Quadrini (2004), instead, examine an economy where the limits in the entrepreneurs' ability to diversify idiosyncratic production risks originate in lack of commitment.

Also related is the literature on credit constraints and entrepreneurial activity (e.g., Bernanke and Gertler, 1989, 1990; Banerjee and Newman, 1993; Kiyotaki and Moore, 1997; Caggeti and De Nardi, 2003; Buera, 2004). Whereas this literature focuses on how wealth may affect the ability to invest when agents face credit constraints, this paper shows how wealth may affect the willingness to invest even in the absence of borrowing constraints. This distinction is important for at least two reasons. First, although credit constraints and uninsurable risks share the prediction that investment is sensitive to wealth, the welfare and policy implications may be quite different. For example, redistributing from the rich to the poor has no impact on aggregate productivity in the model of this paper. Second, the impact of investment risk, unlike that of credit constraints, need not vanish as agents get wealthier. This may help explain the difference with Kocherlakota (2000), who finds the quantitative importance of credit constraints in baseline calibrations of the neoclassical growth model to be limited.

Finally, the paper extends and qualifies the literature that studies the role of rate-of-return risk in linear growth models (e.g., Obstfeld, 1994; Jones, Manuelli, and Stacchetti, 2000; Krebs, 2003). As mentioned above, the results of this literature rely critically on the assumption that agents do not have any fixed source of income beyond their capital. Moreover, this literature obtains tractability only by eliminating transitional dynamics and therefore does not examine the business-cycle implications of incomplete markets.

The rest of the paper is organized as follows. Section 2 introduces the basic model. Section 3 characterizes the general equilibrium and Section 4 analyzes the steady state. Section 5 introduces public equity and Section 6 examines the transitional dynamics. Section 7 concludes. All proofs are in the Appendix.

\footnotetext{
${ }^{4}$ See especially Krusell and Smith (1997) and Castañeda, Diaz-Giménez, and Ríos-Rull (2003).
} 


\section{The Model}

Time is discrete, indexed by $t \in\{0,1, \ldots, \infty\}$. The economy is populated by a continuum of infinitelylived households, indexed by $i$ and distributed uniformly over $[0,1]$. All firms in the economy are privately held, and each household owns a single firm, so that firm $i$ is identified as the firm owned by household $i$. Firms employ labor in a competitive labor market but use the capital stock accumulated by their respective household-owner. Households, on the other hand, are each endowed with one unit of labor, which they supply inelasticly in the competitive labor market; they can invest capital in the firm they own, but in no other firm; and they can freely trade a riskless bond, but can not diversify the idiosyncratic risk in their capital income.

Preferences. I assume a Kreps-Porteus/Epstein-Zin (KPEZ) specification with constant elasticity of intertemporal substitution (CEIS) and constant relative risk aversion (CRRA). A stochastic consumption stream $\left\{c_{t}^{i}\right\}_{t=0}^{\infty}$ generates a stochastic utility stream $\left\{u_{t}^{i}\right\}_{t=0}^{\infty}$ according to the recursion

$$
u_{t}^{i}=U\left(c_{t}^{i}\right)+\beta \cdot U\left\{\mathbb{C E}_{t}\left[U^{-1}\left(u_{t+1}^{i}\right)\right]\right\}
$$

where $\mathbb{C E}_{t}\left(u_{t+1}^{i}\right) \equiv \Upsilon^{-1}\left[\mathbb{E}_{t} \Upsilon\left(u_{t+1}^{i}\right)\right]$. The utility functions $U$ and $\Upsilon$ aggregate consumption across dates and states, respectively, and are given by

$$
U(c)=\frac{c^{1-1 / \theta}}{1-1 / \theta} \quad \text { and } \quad \Upsilon(c)=\frac{c^{1-\gamma}}{1-\gamma},
$$

where $\theta>0$ is the elasticity of intertemporal substitution and $\gamma>0$ is the coefficient of relative risk aversion. The quantity $\mathbb{C E}_{t}\left(u_{t+1}\right)$ represents the certainty equivalent of $u_{t+1}$ conditional on period- $t$ information.

None of the results of the paper relies on the KPEZ preference specification. Standard expected utility is nested by letting $\theta=1 / \gamma$, in which case (1) reduces to

$$
u_{t}=\mathbb{E}_{t} \sum_{s=0}^{\infty} \beta^{s} \frac{\left(c_{t+s}\right)^{1-\gamma}}{1-\gamma} .
$$

I nevertheless find it useful to allow $\theta \neq 1 / \gamma$ for two reasons: first, to clarify that the sign of the steady-state effect of incomplete markets depends on the elasticity of intertemporal substitution, not the degree of risk aversion; and second, to explore in more detail the quantitative properties of the model.

Budgets. Let $\omega_{t}$ denote the wage rate in period $t$ and $R_{t}$ the gross risk-free rate between periods $t-1$ and $t$. The budget constraint of household $i$ in period $t$ is given by

$$
c_{t}^{i}+k_{t+1}^{i}+b_{t+1}^{i}=\pi_{t}^{i}+R_{t} b_{t}^{i}+\omega_{t}
$$


where $c_{t}^{i}$ denotes consumption, $k_{t+1}^{i}$ investment in physical capital, $b_{t+1}^{i}$ savings in the risk-free bond, and $\pi_{t}^{i}$ capital income (or the value of firm $i$, to be specified below). ${ }^{5}$ Naturally, consumption and physical capital can not be negative: $c_{t}^{i} \geq 0$ and $k_{t+1}^{i} \geq 0$. Finally, households can freely borrow in the riskless bond up to the "natural" solvency constraint that debt is low enough to be paid out even under the worst realization of idiosyncratic uncertainty. ${ }^{6}$

Technology and idiosyncratic risk. The capital income of household $i$ is given by the earnings of firm $i$ net of labor costs:

$$
\pi_{t}^{i}=y_{t}^{i}-\omega_{t} n_{t}^{i}
$$

where $n_{t}^{i}$ denotes the amount of labor firm $i$ hires in period $t$ and $y_{t}^{i}$ the gross output it produces in the same period. Output in turn is given by

$$
y_{t}^{i}=F\left(k_{t}^{i}, n_{t}^{i}, A_{t}^{i}\right)
$$

where $F: \mathbb{R}_{+}^{3} \rightarrow \mathbb{R}_{+}$is a neoclassical production technology - that is, $F$ exhibits constant returns to scale (CRS) with respect to $K$ and $L$, has positive and strictly diminishing marginal products, and satisfies the familiar Inada conditions - and $A_{t}^{i}$ represents an exogenous production shock specific to firm $i$.

The shock $A_{t}^{i}$ is realized in the beginning of every period $t$, after capital $k_{t}^{i}$ has been installed but before employment $n_{t}^{i}$ is chosen. It is independently and identically distributed across $i$ and $t$, with continuous p.d.f. $\psi: \mathbb{R}_{+} \rightarrow \mathbb{R}_{+}$. In order to interpret a higher $A_{t}^{i}$ as higher productivity (or higher profitability), I impose $F_{A}>0, F_{K A}>0$, and $F_{L A}>0$. I finally let $F(K, L, 0)=0$, meaning that the worst idiosyncratic event leads to zero output, and normalize $\bar{A} \equiv \int A \psi(A) d A=1$.

Equilibrium. Households choose plans $\left\{c_{t}^{i}, n_{t}^{i}, k_{t+1}^{i}, b_{t+1}^{i}\right\}_{t=0}^{\infty}$ contingent on the history of their idiosyncratic shocks so as to maximize their life-time utility. Idiosyncratic uncertainty, however, washes out at the aggregate. I thus define an equilibrium as a deterministic sequence of prices $\left\{\omega_{t}, R_{t}\right\}_{t=0}^{\infty}$, a deterministic macroeconomic path $\left\{C_{t}, K_{t}, Y_{t}\right\}_{t=0}^{\infty}$, and a collection of contingent plans $\left\{c_{t}^{i}, n_{t}^{i}, k_{t+1}^{i}, b_{t+1}^{i}\right\}_{t=0}^{\infty}, i \in[0,1]$, such that the following conditions hold: ${ }^{7}$

(i) Optimality: $\quad\left\{c_{t}^{i}, n_{t}^{i}, k_{t+1}^{i}, b_{t+1}^{i}\right\}_{t=0}^{\infty}$ maximizes $u_{0}^{i}$ for every $i$

(ii) Labor-market clearing: $\quad \int_{i} n_{t}^{i}=1$ in all $t$

(iii) Bond-market clearing: $\quad \int_{i} b_{t}^{i}=0$ in all $t$

(iv) Aggregation: $\quad C_{t}=\int_{i} c_{t}^{i}, Y_{t}=\int_{i} y_{t}^{i}, K_{t}=\int_{i} k_{t}^{i}$ in all $t$

\footnotetext{
${ }^{5}$ Note that the budget constraint is expressed in terms of stock variables: $R_{t}$ equals 1 plus the net risk free rate and $\pi_{t}^{i}$ includes the value of the beginning-of-period non-depreciated capital stock installed in firm $i$.

${ }^{6}$ As shown in Aiyagari (1994), given the non-negativity of consumption, this constraint is equivalent to imposing a non-Ponzi game condition.

${ }^{7}$ With some abuse of notation, whenever I write $\int_{i} x_{t}^{i}$ for some variable $x$, I mean the cross-sectional expectation of $x$ in period $t$.
} 


\section{Equilibrium Characterization}

\subsection{Individual behavior}

The idiosyncratic state of agent $i$ in period $t$ is summarized by $\left(k_{t}^{i}, b_{t}^{i}, A_{t}^{i}\right)$ and therefore the value function, for given price sequence, can be denoted by $V(k, b, A ; t)$. Since, by the assumption that $F(K, L, 0)=0$, the worst possible realization of capital income is zero, the natural solvency constraint reduces to $b_{t+1}^{i} \geq-h_{t}$, where

$$
h_{t} \equiv \sum_{j=1}^{\infty} \frac{\omega_{t+j}}{R_{t+1} \ldots R_{t+j}}
$$

denotes the present value of future labor income (a.k.a. "human wealth"). It follows that the household's problem can be represented by the following dynamic program:

$$
\begin{gathered}
V(k, b, A ; t)=\max _{c, n, k, b} U(c)+\beta \cdot U \Upsilon^{-1}\left\{\int\left[\Upsilon U^{-1} V\left(k^{\prime}, b^{\prime}, A^{\prime} ; t+1\right)\right] d \Psi\left(A^{\prime}\right)\right\} \\
\text { s.t. } \quad \begin{aligned}
c & +k^{\prime}+b^{\prime}=\pi+R b+\omega \\
\pi & =F(k, n, A)-\omega n \\
c & \geq 0 \quad k^{\prime} \geq 0 \quad b^{\prime} \geq-h_{t}
\end{aligned}
\end{gathered}
$$

When $\theta=1 / \gamma$, the above reduces to the more familiar Bellman equation, $V(\cdot ; t)=\max \{U(\cdot)+$ $\left.\beta \mathbb{E}_{t} V(\cdot ; t+1)\right\}$.

This problem is next solved in two steps: first, for the optimal labor demand of firm $i$; then, for the optimal consumption, savings and investment of household $i$.

Labor demand and capital income. Labor demand $n_{t}^{i}$ affects only earnings $\pi_{t}^{i}$ in period $t$ and is chosen after the capital stock $k_{t}^{i}$ has been installed and the contemporaneous shock $A_{t}^{i}$ has been observed. It follows that the optimal $n_{t}^{i}$ maximizes $\pi_{t}^{i}$ state by state. Moreover, by CRS, the optimal $n_{t}^{i}$ and the maximal $\pi_{t}^{i}$ are linear in $k_{t}^{i}$ : the individual firm can always adjust its employment in proportion to its capital stock, implying that the individual household faces linear returns in his investment.

Lemma 1 Given $\left(\omega_{t}, A_{t}^{i}, k_{t}^{i}\right)$, labor demand and capital income are linear in $k_{t}^{i}$, decreasing in $\omega_{t}$, and increasing in $A_{t}^{i}$ :

$$
n_{t}^{i}=n\left(A_{t}^{i}, \omega_{t}\right) k_{t}^{i} \quad \text { and } \quad \pi_{t}^{i}=r\left(A_{t}^{i}, \omega_{t}\right) k_{t}^{i},
$$

where $r(A, \omega) \equiv \max _{L}[F(1, L, A)-\omega L]$ and $n(A, \omega) \equiv \arg \max _{L}[F(1, L, A)-\omega L]$.

Savings and investment. Let $w_{t}^{i} \equiv \pi_{t}^{i}+R_{t} b_{t}^{i}+\omega_{t}$ denote the financial (or "non-human") wealth of household $i$ in period $t$. The budget constraint reduces to $c_{t}^{i}+k_{t+1}^{i}+b_{t+1}^{i}=w_{t}^{i}$. Moreover, by Lemma 1,

$$
w_{t}^{i}=r\left(A_{t}^{i}, \omega_{t}\right) k_{t}^{i}+R_{t} b_{t}^{i}+\omega_{t} .
$$


Finally, note that conditioning on $\left(k_{t}^{i}, b_{t}^{i}, A_{t}^{i}\right)$ is useful only for evaluating the optimal $n_{t}^{i}$ and the associated $w_{t}^{i}$ in (8). It follows that the household's savings problem reduces to

$$
\begin{array}{r}
V(w ; t)=\max _{\left(c, k^{\prime}, b^{\prime}\right) \in \mathbb{R}_{+} \times\left[-h_{t}, \infty\right)} U(c)+\beta \cdot U \Upsilon^{-1}\left\{\int\left[\Upsilon U^{-1} V\left(w^{\prime} ; t+1\right)\right] d \Psi\left(A^{\prime}\right)\right\} \\
\text { s.t. } \quad c+k^{\prime}+b^{\prime}=w, \quad w^{\prime}=r\left(A^{\prime}, \omega_{t+1}\right) k^{\prime}+R_{t+1} b^{\prime}+\omega_{t+1},
\end{array}
$$

where, with slight abuse of notation, $V$ now denotes the value function in terms of financial wealth.

This problem is formally similar to the classic portfolio problem studied by Samuelson (1969) and Merton (1969): preferences are homothetic (by assumption) and wealth is linear in all assets (by Lemma 1). That the risky asset is physical investment in a privately-held business rather than a financial security, that the payoff of this asset depends on the wage rate and thereby on the aggregate capital stock, or that the risk is idiosyncratic, are important for the general equilibrium of the economy, but do not affect the mathematical properties of the individual's decision problem.

Lemma 2 Given prices, optimal consumption, investment and bond holdings are linear in wealth:

$$
\begin{aligned}
c_{t}^{i} & =\left(1-s_{t}\right)\left(w_{t}^{i}+h_{t}\right) \\
k_{t+1}^{i} & =s_{t} \phi_{t}\left(w_{t}^{i}+h_{t}\right) \\
b_{t+1}^{i} & =s_{t}\left(1-\phi_{t}\right)\left(w_{t}^{i}+h_{t}\right)-h_{t}
\end{aligned}
$$

where $w_{t}^{i}$ and $h_{t}$ are given by (8) and (5) and

$$
\begin{aligned}
s_{t} & =\frac{1}{1+\left(\sum_{\tau=t}^{\infty} \prod_{j=t}^{\tau} \beta^{\theta} \rho_{j}^{\theta-1}\right)^{-1}} \\
\rho_{t} & =\rho\left(\omega_{t+1}, R_{t+1}\right) \equiv \max _{\varphi \in[0,1]}\left\{\int\left[\varphi r\left(A, \omega_{t+1}\right)+(1-\varphi) R_{t+1}\right]^{1-\gamma} \psi(A) d A\right\}^{\frac{1}{1-\gamma}} \\
\phi_{t} & =\phi\left(\omega_{t+1}, R_{t+1}\right) \equiv \arg \max _{\varphi \in[0,1]}\left\{\int\left[\varphi r\left(A, \omega_{t+1}\right)+(1-\varphi) R_{t+1}\right]^{1-\gamma} \psi(A) d A\right\}^{\frac{1}{1-\gamma}}
\end{aligned}
$$

To interpret the above conditions, note that the sum $w_{t}^{i}+h_{t}$ represents the "effective" wealth of household $i, s_{t}$ is the saving rate out of effective wealth, $\phi_{t}$ is the fraction of savings allocated to capital, and $\rho_{t}$ is the risk-adjusted return to savings (a.k.a. the certainty equivalent of the overall portfolio return). Condition (13) follows from the Euler condition and gives the saving rate as a function of current and future risk-adjusted returns. Because of the familiar income and substitution effects, this is an increasing function if $\theta>1$, a decreasing one if $\theta<1$, and reduces to a constant, $s_{t}=\beta$, if $\theta=1$. Conditions (15) and (14), on the other hand, mean that the allocation of savings between private equity and bonds maximizes the risk-adjusted return to savings.

To gain more intuition behind (15) and (14), we can follow Campbell and Viceira (2002) in approximating the optimal $\phi_{t}$ and $\rho_{t}$ by

$$
\phi_{t} \approx \frac{\ln \bar{r}_{t+1}-\ln R_{t+1}}{\gamma \sigma_{t+1}^{2}} \quad \text { and } \quad \rho_{t} \approx R_{t+1} \exp \left\{\frac{\left(\ln \bar{r}_{t+1}-\ln R_{t+1}\right)^{2}}{2 \gamma \sigma_{t+1}^{2}}\right\}
$$


where $\bar{r}_{t+1} \equiv \mathrm{E}_{t}\left[r\left(A_{t+1}, \omega_{t+1}\right)\right]$ and $\sigma_{t+1} \equiv \operatorname{Var}_{t}\left[\ln r\left(A_{t+1}, \omega_{t+1}\right)\right] .{ }^{8}$ Hence, both the optimal share of savings allocated to private capital and the resulting risk-adjusted return decrease with either the idiosyncratic volatility $\sigma_{t+1}$ or the anticipated wage rate $\omega_{t+1}$. On the other hand, an increase in the risk free rate $R_{t+1}$ lowers $\phi_{t}$ but raises $\rho_{t}$. The effects of $\sigma_{t+1}$ and $R_{t+1}$ are obvious; the effect of $\omega_{t+1}$ reflects the fact that an increase in the wage rate reduces firm earnings and capital returns for every realization of the productivity shock.

\subsection{General equilibrium}

By Lemma 1 and the fact that there is a continuum of agents and the shocks are i.i.d. across them, aggregate employment and capital income are given by $N_{t}=\int_{i} n_{t}^{i}=\bar{n}\left(\omega_{t}\right) K_{t}$ and $\Pi_{t}=\int_{i} \pi_{t}^{i}=$ $\bar{r}\left(\omega_{t}\right) K_{t}$, where $\bar{n}(\omega) \equiv \int n(A, \omega) \psi(A) d A$ and $\bar{r}(\omega) \equiv \int r(A, \omega) \psi(A) d A$. It follows that the labor market clears in period $t$ if and only if $\omega_{t}=\omega\left(K_{t}\right)$, where $\omega(K) \equiv \bar{n}^{-1}(1 / K)$. Similarly, aggregate gross output - including non-depreciated capital - is given by $Y_{t}=\int_{i} y_{t}^{i}=\Pi_{t}+\omega_{t}=f\left(K_{t}\right)$, where $f(K) \equiv \bar{r}(\omega(K)) K+\omega(K)$. Lemma 2, in turn, consumption, bond holdings, and private investment are linear in individual wealth and therefore the corresponding aggregates are not affected by wealth inequality. Using these properties and aggregating across agents, we conclude to the following closed-form recursive characterization of the general equilibrium.

Proposition 1 (General Equilibrium) In equilibrium, the aggregate dynamics satisfy

$$
\begin{gathered}
C_{t}+K_{t+1}=Y_{t}=f\left(K_{t}\right) \\
C_{t}=\left(1-s_{t}\right)\left[f\left(K_{t}\right)+H_{t}\right] \\
\left(1-s_{t}\right)^{-1}=1+\beta^{\theta} \rho_{t+1}^{\theta-1}\left(1-s_{t+1}\right)^{-1} \\
K_{t+1}=\phi_{t} s_{t}\left[f\left(K_{t}\right)+H_{t}\right] \\
\bar{n}\left(\omega_{t}\right) K_{t}=1 \\
H_{t}=\frac{\omega_{t+1}+H_{t+1}}{R_{t+1}}
\end{gathered}
$$

where $\phi_{t}=\phi\left(\omega_{t+1}, R_{t+1}\right)$ and $\rho_{t}=\rho\left(\omega_{t+1}, R_{t+1}\right)$.

The interpretation of these conditions is straightforward. (17) is the resource constraint. (18) and (19) give aggregate consumption and the associated Euler condition. (20) gives the aggregate capital stock and (21) the clearing condition for the labor market. (22) is the present value of aggregate labor income in recursive form.

Finally, to see more clearly that the system is recursive, use (17), (21) and (22) to eliminate $C_{t}$, $\omega_{t}$, and $R_{t+1}$. The equilibrium dynamics then reduce to a three-dimension, first-order, differenceequation system in $\left(K_{t}, H_{t}, s_{t}\right)$. This is a dramatic gain in tractability as compared to most other

\footnotetext{
${ }^{8}$ See the Appendix for the derivation of condition (16).
} 
incomplete-markets models, in which the equilibrium dynamics are characterized by a recursion over the entire wealth distribution - an infinitely-dimensional object. The simple structure of the equilibrium recursion is further exploited in Section 6.2, when I analyze the transitional dynamics.

\section{$4 \quad$ Steady State}

\subsection{Characterization}

A steady state is a fixed point of the dynamic system (17)-(21). ${ }^{9}$ Since the general equilibrium was characterized in closed form for any kind of idiosyncratic risk, so does the steady state as well. For expositional simplicity, however, it is most useful to consider the case that the productivity shock is augmented to capital and lognormally distributed. I thus henceforth assume

Assumption A1. $F(K, L, A)=F(A K, L, 1)$ and $\ln A \sim \mathcal{N}\left(-\sigma^{2} / 2, \sigma^{2}\right)$.

The standard deviation $\sigma$ then parsimoniously parameterizes the amount of uninsured idiosyncratic risk in private production and investment. ${ }^{10}$

Proposition 2 (Steady State) In steady state, the capital stock $K$ and the interest rate $R$ solve

$$
\begin{gathered}
\beta^{\theta} \rho^{\theta-1}\left[\phi f^{\prime}(K)+(1-\phi) R\right]=1 \\
\frac{f(K)-f^{\prime}(K) K}{(R-1) K}=\frac{1-\phi}{\phi}
\end{gathered}
$$

where $\phi=\phi(\omega(K), R)$ and $\rho=\rho(\omega(K), R)$.

Condition (23) follows from combining the resource constraint with the Euler condition and has a simple interpretation. The first term in the left-hand side of $(23), s=\beta^{\theta} \rho^{\theta-1}$, is the steadystate value of the saving rate; this is increasing (respectively, decreasing) in the risk-adjusted return $\rho$ if and only if $\theta>1(\theta<1)$ and reduces to $s=\beta$ when $\theta=1$. The second term, $\phi f^{\prime}(K)+(1-\phi) R$, represents the aggregate return to savings; this is a weighted average of the marginal product of capital and the risk-free rate. The product of these two terms gives the growth rate of aggregate effective wealth. In the steady state, aggregate wealth must be constant, which gives (23). Condition (24), on the other hand, follows from clearing the bond market and requires

\footnotetext{
${ }^{9}$ Although aggregates are well defined at the steady state, individual wealth is a martingale and there is no stationary wealth distribution. This is not uncommon in incomplete-market models, but here it can easily be fixed with the following modification: in every period, let a mass $\lambda \in(0,1)$ of randomly selected households die and be replaced with an equal mass of new-born households; and let the assets of the dead households be distributed uniformly among the new-born households.

${ }^{10}$ A1 implies that $f(K)=F(K, 1,1)$ and $\bar{r}(\omega(K))=F_{K}(K, 1,1)=f^{\prime}(K)$, for every $\sigma \geq 0$ and every $K>0$, so that an increase in $\sigma$ is indeed equivalent to a mean-preserving spread in individual returns.
} 
that the ratio of the present value of labor income to the capital stock is consistent with the individuals' optimal allocation of savings between private equity and the riskless bond.

When markets are complete, the optimality condition for $\phi$ reduces to the familiar arbitrage condition $f^{\prime}(K)=R$. Condition (23) then reduces to $R=1 / \beta$ and finally (24) pins down $\phi$. When, instead, markets are incomplete, (23) pins a unique $K$ for any given $R$. Condition (24) then can be solved for $R$. Clearly, it must be that $R<1 / \beta$, or otherwise aggregate consumption would explode to infinity and a steady state would not exist. Most importantly, it must be that $f^{\prime}(K)>R$, or otherwise agents would hold no capital in equilibrium and a steady state would again not exist. In other words, the precautionary motive implies a reduction in the interest rate $(R<1 / \beta)$, but the investment risk introduces a premium on capital $\left(f^{\prime}(K)>R\right)$, thus leaving open the possibility that either $f^{\prime}(K)<1 / \beta$ or $f^{\prime}(K)>1 / \beta$. That is, the overall effect of idiosyncratic investment risk on the capital stock is ambiguous. In contrast, in Bewley models like Aiyagari (1994), only the precautionary motive is present, the steady state satisfies $f^{\prime}(K)=R<1 / \beta$, and the impact of incomplete markets on savings is unambiguously positive.

To understand the steady-state effect of investment risk, it is useful to assume for a moment that $R$ is exogenously fixed, which would have been the case if the economy were open to an international market for the riskless bond. We can then show (see Appendix) that, for any $R \in(1,1 / \beta)$, the steady-state capital stock is approximately given by

$$
\ln f^{\prime}(K) \approx \ln R+\sigma \sqrt{\frac{2 \gamma \theta}{1+\theta}[-\ln (\beta R)]}
$$

The above, of course, reduces to $f^{\prime}(K)=R$ when $\sigma=0$. When $\sigma>0, K$ decreases with $\sigma$ for two reasons. First, there is a direct decision-theoretic effect in that an increase in risk discourages private investment for any level of wealth. Second, there is an indirect general-equilibrium effect in that, as all agents cut back in their investments, aggregate income and wealth fall in equilibrium, which in turn further discourages risk taking and private investment. This effect is present only because risk taking is sensitive to individual wealth and introduces a "multiplier" (a complementarity), which helps explain the relatively large quantitative effects reported later on. ${ }^{11}$

In a closed economy, however, the interest rate adjusts to any change in the level of idiosyncratic risks so as to ensure that the aggregate excess demand for the riskless bond is zero, which is what condition (24) imposes. An increase in $\sigma$ now implies also a reduction in $R$, which counteracts with the increase in the risk premium on private investment and makes the overall effect of incomplete markets on the capital stock ambiguous in general. Since the sensitivity of savings to the interest

\footnotetext{
${ }^{11}$ In an open economy, the steady-state levels of aggregate wealth and consumption are also uniquely determined, for any $R<1 / \beta$. This is unlike complete markets, where the steady-state levels of aggregate wealth and consumption move one-to-one with their corresponding initial levels. A multi-country extension of the model could thus generate a stationary wealth distribution for the world economy, with cross-country differences in capital, wealth and consumption being explained by cross-country differences in the degree of domestic risk sharing.
} 
rate is determined by the elasticity of intertemporal substitution, one may expect that the effect of a higher risk dominates the effect of a lower interest rate unless the elasticity of intertemporal substitution is sufficiently small. This intuition is verified in the following.

Proposition 3 There exists $\underline{\theta}<1$ such that the steady-state levels of capital, output, wages, and consumption are lower under incomplete markets if and only if $\theta>\underline{\theta}$. For small $\sigma$,

$$
\underline{\theta} \approx \frac{R-1}{f(K) / K-1} \leq \alpha,
$$

where $\alpha$ is the income share of capital.

In linear-growth $(A K)$ models, idiosyncratic investment risk reduces steady-state savings if and only if $\theta>1$. This is not inconsistent with the result stated above. In an $A K$ economy, capital income exhausts all income in the economy, so that $R=f(K) / K$ and $\underline{\theta}=\alpha=1$. In a neoclassical economy, instead, capital income is only a fraction of total income, so that $\underline{\theta} \leq \alpha<1$. In other words, it is the existence of labor income (or other sources of wealth) that explains why the critical threshold for the elasticity of intertemporal substitution is lower in the neoclassical growth paradigm than in the $A K$ paradigm.

The above result is not only of theoretical interest. Given that most empirical estimates of the elasticity of intertemporal substitution suggest a value between 0.5 and 1 , the $A K$ paradigm predicted that financial innovation in the form of better risk sharing is likely to reduce aggregate savings. Proposition 3 reverts this prediction: in the context of the neoclassical growth model, better risk sharing in investment is likely to boost capital accumulation.

Indeed, for most plausible parameter values, $\underline{\theta}$ is well below most estimates of the elasticity of intertemporal substitution. For example, when the discount rate is $5 \%$, the ratio of capital to output is 3 , and the depreciation rate is $5 \%$, (26) gives $\underline{\theta}=(.05) /(.33-.05)=0.17$; with $5 \%$ to $10 \%$ discount and depreciation rates, $\underline{\theta}$ remains in the neighborhood of 0.2 even when the income share of capital is as high as $60 \%$ or $70 \%$. In what follows, I focus on calibrated versions of the model and make a first attempt at quantifying the impact of idiosyncratic investment risk.

\subsection{Numerical results}

Thanks to the tractability of the model, the numerical solution of the steady state is trivial: substituting $\phi=\phi(\omega(K), R)$ and $\rho=\rho(\omega(K), R)$ into (23)-(24) gives a simple system of two equations in two unknowns, the steady-state levels of $K$ and $R$.

With a Cobb-Douglas technology and a lognormal productivity, the economy is fully parameterized by $(\beta, \gamma, \theta, \alpha, \delta, \sigma)$. The calibration of preferences and technologies $(\beta, \gamma, \theta, \alpha, \delta)$ is standard: for my benchmark calibration, I let the time period be one year, the discount rate $1-\beta^{-1}=5 \%$, the coefficient of relative risk aversion $\gamma=2$, the elasticity of intertemporal substitution $\theta=1$, the 
income share of capital $\alpha=40 \%$, and the depreciation rate $\delta=5 \%$. What is difficult to measure is $\sigma$, the standard deviation of the individual return in private equity. ${ }^{12}$

There are many indications that idiosyncratic investment risks are quantitatively large. The estimated value of private equity in the United States is about as high as the value of public equity today - it was about twice as large in the 70's and 80 's. More than $75 \%$ of aggregate private equity is owned by households for whom private equity constitutes at least half of their total net worth. The median rich household ("rich" being defined as the top 1-5\% of the wealth distribution) holds almost $60 \%$ of its non-housing wealth in private equity; and more than $70 \%$ of that is invested in a single company in which the household has an active management interest. The probability that a privately-held firm survives over the first 5 years of its life is only 37 percent; and the variation in private investment returns is very large even conditional on survival. For further details on these facts, see Carrol (2001) and Moskowitz and Vissing-Jørgensen (2002).

Despite these indications, unfortunately there are no available estimates of the level of idiosyncratic investment risk. For example, Moskowitz and Vissing-Jørgensen (2002) and Bitler, Moskowitz, and Vissing-Jørgensen (2005) explore the cross-section of private-equity investors in the Survey of Consumer Finances, but are unable to provide a reliable measure for the standard deviation of individual returns because of the lack of enough time-series variation in the data. For their numerical exercises, they instead proxy $\sigma$ with the standard deviation of the annual return to an individual publicly-traded stock. In lack of a better alternative, I also follow the same strategy.

Campbell et al. (2001) report that the standard deviation of the annual return to a publiclytraded stock is around $50 \%$. One possibility is that privately-held firms, being on average younger and smaller than publicly-held firms, face even higher risks. Another possibility, however, is that publicly-held firms are willing to engage in more risky projects than privately-held firms. One may thus argue that $50 \%$ is an upper bound for $\sigma$. On the other hand, the overall stock-market volatility, which pools all idiosyncratic risk and is about $17 \%$, provides a lower bound for $\sigma$. On the basis of these facts, I consider $20 \%$ to $40 \%$ as a plausible range for $\sigma$.

The results are presented in Table 1 . The first raw of the table corresponds to $\sigma=40 \%$ and the second to $\sigma=20 \%$. The rest of the Table does a series of robustness checks for different values of $\gamma, \theta, \beta, \alpha$, and $\delta .^{13}$

\footnotetext{
${ }^{12}$ To see that $\sigma$ is the standard deviation of investment returns, note that, under $\mathrm{A} 1, \ln r(A, \omega)=\ln A+\ln \bar{r}(\omega)$ and therefore $\operatorname{Var}_{t}\left[\ln r\left(A_{t+1}, \omega_{t+1}\right)\right]^{1 / 2}=\sigma$. Alternatively, one can interpret $A_{t+1}$ as an idiosyncratic shock in the depreciation of capital, in which case $\delta$ is the mean and $\sigma$ the standard deviation of the rate of depreciation.

${ }^{13}$ For all the quantitative results, aggregate income is measured by $G D P_{t} \equiv f\left(K_{t}\right)-(1-\delta) K_{t}=K_{t}^{\alpha}$; the risk-free rate and the mean excess return on private equity by $R_{t}-1$ and $\bar{r}_{t}-R_{t}$, respectively; and the saving rate by $I_{t} / G D P_{t}$, where $I_{t}=K_{t+1}-(1-\delta) K_{t}$.
} 


\begin{tabular}{|c|c|c|c|c|c|c|c|c|c|}
\hline $\boldsymbol{\sigma}$ & $\gamma$ & $\theta$ & $\beta^{-1}-1$ & $\alpha$ & $\delta$ & $\begin{array}{c}\Delta \text { (Saving } \\
\text { Rate) }\end{array}$ & $\Delta($ GDP) & $\begin{array}{c}\text { Interest } \\
\text { Rate }\end{array}$ & $\begin{array}{c}\text { Private } \\
\text { Premium }\end{array}$ \\
\hline $40 \%$ & \multirow{2}{*}{2} & \multirow{2}{*}{1} & \multirow{2}{*}{$5 \%$} & \multirow{2}{*}{$40 \%$} & \multirow{2}{*}{$5 \%$} & $-6.0 \%$ & $-21 \%$ & $4.16 \%$ & $4.94 \%$ \\
\hline $20 \%$ & & & & & & $-2.4 \%$ & $-8 \%$ & $4.62 \%$ & $1.69 \%$ \\
\hline $40 \%$ & \multirow{2}{*}{4} & \multirow{4}{*}{1} & \multirow{4}{*}{$5 \%$} & \multirow{4}{*}{$40 \%$} & \multirow{4}{*}{$5 \%$} & $-8.4 \%$ & $-31 \%$ & $3.90 \%$ & $8.07 \%$ \\
\hline $20 \%$ & & & & & & $-4.2 \%$ & $-14 \%$ & $4.40 \%$ & $3.02 \%$ \\
\hline $40 \%$ & \multirow{2}{*}{1} & & & & & $-3.7 \%$ & $-14 \%$ & $4.42 \%$ & $2.89 \%$ \\
\hline $20 \%$ & & & & & & $-1.3 \%$ & $-5 \%$ & $4.78 \%$ & $0.90 \%$ \\
\hline $40 \%$ & \multirow{4}{*}{2} & \multirow{2}{*}{2} & \multirow{4}{*}{$5 \%$} & \multirow{4}{*}{$40 \%$} & \multirow{4}{*}{$5 \%$} & $-6.4 \%$ & $-22 \%$ & $4.35 \%$ & $5.04 \%$ \\
\hline $20 \%$ & & & & & & $-2.6 \%$ & $-9 \%$ & $4.71 \%$ & $1.70 \%$ \\
\hline $40 \%$ & & \multirow{2}{*}{$1 / 2$} & & & & $-5.4 \%$ & $-19 \%$ & $3.83 \%$ & $4.75 \%$ \\
\hline $20 \%$ & & & & & & $-2.2 \%$ & $-7 \%$ & $4.45 \%$ & $1.66 \%$ \\
\hline $40 \%$ & \multirow{6}{*}{2} & \multirow{6}{*}{1} & \multirow{2}{*}{$5 \%$} & \multirow{2}{*}{$40 \%$} & \multirow{2}{*}{$10 \%$} & $-5.3 \%$ & $-14 \%$ & $4.42 \%$ & $4.12 \%$ \\
\hline $20 \%$ & & & & & & $-1.7 \%$ & $-5 \%$ & $4.78 \%$ & $1.30 \%$ \\
\hline $40 \%$ & & & \multirow{2}{*}{$10 \%$} & \multirow{2}{*}{$40 \%$} & \multirow{2}{*}{$5 \%$} & $-3.6 \%$ & $-19 \%$ & $8.64 \%$ & $6.59 \%$ \\
\hline $20 \%$ & & & & & & $-1.4 \%$ & $-7 \%$ & $9.36 \%$ & $2.16 \%$ \\
\hline $40 \%$ & & & \multirow{2}{*}{$5 \%$} & \multirow{2}{*}{$60 \%$} & \multirow{2}{*}{$5 \%$} & $-11.2 \%$ & $-49 \%$ & $3.23 \%$ & $7.25 \%$ \\
\hline $20 \%$ & & & & & & $-4.7 \%$ & $-23 \%$ & $4.05 \%$ & $2.69 \%$ \\
\hline
\end{tabular}

Table 1: The steady-state effects of idiosyncratic investment risk. $\Delta$ (Saving Rate) is the change in the aggregate saving rate between complete and incomplete markets, and $\triangle(G D P)$ the corresponding percentage change in the aggregate level of income; interest rate is the rate of return on the riskless bond under incomplete markets; and private premium is the mean excess return on private equity.

Under the benchmark calibration, the reduction in the steady-state saving rate varies between 2.4 and 6 percentage points as $\sigma$ varies between $20 \%$ and $40 \%$. The steady-state capital stock falls by $19 \%-45 \%$ and the steady-state level of income by $8 \%-21 \%$. The risk-free rate falls from $5 \%$ under complete markets to $4.6 \%$ when $\sigma=20 \%$ and $4.2 \%$ when $\sigma=40 \%$. Finally, the associated risk premium on private equity is $1.7 \%$ when $\sigma=20 \%$ and $4.9 \%$ when $\sigma=40 \%$.

As shown in Table 1, the large negative effect of idiosyncratic risk on aggregate savings and output appears robust to other plausible calibrations of the model. As expected, increasing (decreasing) the degree of risk aversion raises (reduces) the losses in capital and output. Perhaps more surprisingly, letting the elasticity of intertemporal substitution be either as high as 2 or as low as $1 / 2$ has little effect on the magnitude of capital and output losses. Indeed, $\theta$ would have to fall well below $\alpha$ for the effects to flip sign. Finally, the discount rate and the depreciation rate have modest effects, whereas quite strong is the impact of a broader definition of capital (a higher $\alpha$ ). 


\section{Two Sectors: Private and Public Equity}

The analysis so far has assumed that all investment is subject to idiosyncratic risk. This is not necessarily a bad benchmark for less developed economies, in which production is dominated by privately-held firms. Nevertheless, it is important to understand the robustness of the results to the availability of a safe asset that is in positive net supply. ${ }^{14}$ I thus introduce a second sector of production, to be called "public equity", in which ownership of capital is freely traded across agents and therefore all idiosyncratic risks are fully diversified.

\subsection{General equilibrium}

Let $X_{t}$ and $L_{t}$ denote the total capital and labor allocated to the public-equity sector in period $t$. Total output for this sector is given by $G\left(X_{t}, L_{t}\right)$, where $G$ is a neoclassical production function. Since public equity is risk-free, simple arbitrage implies that its return must equal the return to the riskless bond. Moreover, by profit maximization, $\omega_{t}=G_{L}\left(X_{t}, L_{t}\right)$ and $R_{t}=G_{X}\left(X_{t}, L_{t}\right)$. The rest of the equilibrium characterization is like in the benchmark model. Lemma 1 remains unaffected, whereas Lemma 2 extends with a minor modification, namely replacing bond holdings with the sum of bond and public-equity holdings. We can thus show the following.

Proposition 4 (General Equilibrium) In an equilibrium in which both sectors are active, the aggregate dynamics satisfy

$$
\begin{gathered}
C_{t}+K_{t+1}+X_{t+1}=Y_{t}=F\left(K_{t}, N_{t}, 1\right)+G\left(X_{t}, L_{t}\right) \\
C_{t}=\left(1-s_{t}\right)\left(Y_{t}+H_{t}\right) \\
\left(1-s_{t}\right)^{-1}=1+\beta^{\theta} \rho_{t}^{\theta-1}\left(1-s_{t+1}\right)^{-1} \\
R_{t}=G_{X}\left(X_{t}, L_{t}\right) \quad \omega_{t}=G_{L}\left(X_{t}, L_{t}\right) \\
K_{t+1}=\phi_{t} s_{t}\left(Y_{t}+H_{t}\right) \quad N_{t}=\bar{n}\left(\omega_{t}\right) K_{t} \\
N_{t}+L_{t}=1 \\
H_{t}=\left(\omega_{t+1}+H_{t+1}\right) / R_{t+1}
\end{gathered}
$$

where $\rho_{t}=\rho\left(\omega_{t+1}, R_{t+1}\right)$ and $\phi_{t}=\phi\left(\omega_{t+1}, R_{t+1}\right)$.

The above conditions have a simple interpretation. (27) is the resource constraint of the economy. (28) and (29) give the equilibrium consumption and the associated Euler condition. (30) are the familiar conditions characterizing the equilibrium capital and employment in public equity, whereas (31) are the analogues for private equity. Finally, (32) is the clearing condition for the labor market and (33) the present value of aggregate labor income in recursive form.

\footnotetext{
${ }^{14}$ In the benchmark model, the net supply of the riskless bond was zero. Nevertheless, agents had an implicit safe asset in positive supply: the present value of their labor income.
} 


\subsection{Steady state}

A steady state in which both sectors are active is a fixed point of the dynamic system (27)-(33). To simplify the analysis, it is useful to assume that the capital intensity of the technology used by public-equity firms is identical to the one in privately-held firms, in which case the productivity difference between two sectors can be parameterized by a single scalar.

Assumption A2. $G(X, L)=F(X, L, 1 / \mu)$ for some $\mu>1$.

If $\mu$ were less than 1 , public equity would dominate private equity and the model would reduce to a standard complete-markets Ramsey economy, which explains why I restrict $\mu>1$. On the other hand, if idiosyncratic risks were too low, all production would take place in the privately-held firms and the model would reduce to the one-sector benchmark analyzed before. Hence, in what follows, I consider the case that both sectors are active in equilibrium.

Let $R(\omega) \equiv \max _{l}[G(1, l)-\omega l]$ and $l(\omega) \equiv \arg \max _{l}[G(1, l)-\omega l]$ and note that $(30)$ holds if and only if $R_{t}=R\left(\omega_{t}\right)$ and $L_{t}=l\left(\omega_{t}\right) X_{t}$. Moreover, under A1 and A2, $\bar{r}\left(\omega_{t}\right)=\mu R_{t}$, meaning that $\mu$ pins down the premium on private equity. By implication, $\rho(\omega, R)=\varrho R$ and $\phi(\omega, R)=\varphi$, where

$$
\begin{aligned}
\varrho & \equiv \max _{\phi \in[0,1]}\left\{\int(\phi A+1-\phi)^{1-\gamma} \psi(A) d A\right\}^{\frac{1}{1-\gamma}} \approx \mu^{1 /\left(2 \gamma \sigma^{2}\right)} \\
\varphi & \equiv \arg \max _{\phi \in[0,1]}\left\{\int(\phi A+1-\phi)^{1-\gamma} \psi(A) d A\right\}^{\frac{1}{1-\gamma}} \approx \ln \mu /\left(\gamma \sigma^{2}\right)
\end{aligned}
$$

Thus, $\varrho$ and $\varphi$ are pinned down by the exogenous parameters $\mu$ and $\sigma$ alone. We can then show the following.

Proposition 5 (Steady State) In a steady state in which both sectors are active:

(i) The interest rate is

$$
R=\beta^{-1} \varrho^{1 / \theta-1}(\varphi \mu+1-\varphi)^{-1 / \theta}<1 / \beta
$$

where $\varphi$ and $\varrho$ are given by (34)-(35); the wage rate is then given by $R(\omega)=R$ and the capital stocks by

$$
K=\frac{1 / l(\omega)+\omega /(R-1)}{\mu+1 / \phi-1} \quad \text { and } \quad X=1 / l(\omega)-\mu K .
$$

(ii) There exists $\underline{\theta}<1$ such that $\theta>\underline{\theta}$ suffices for an increase in $\sigma$ to raise the interest rate and reduce the investment in private equity, total factor productivity, aggregate output, and aggregate consumption.

As compared to the benchmark model, public equity introduces three novel effects.

First, incomplete markets reduce the demand for private equity but increase the demand for public equity. Indeed, since the risk-free rate is necessarily lower than the discount rate, the capitallabor in publicly-traded firms is unambiguously higher than under complete markets. As a result, 
the impact of incomplete markets on aggregate savings may be ambiguous even for relatively high elasticities of intertemporal substitution.

Second, an increase in idiosyncratic risk triggers a reallocation of resources (both capital and labor) from the more risky but more productive sector (private equity) to the less risky but less productive one (public equity), thus causing a reduction in aggregate total factor productivity. As a result, aggregate output may fall even if aggregate capital does not.

Third, even though the risk-free rate is always below the discount rate, an increase in risk may locally increase the risk-free rate when both private and public equity are held. This is unlike either the Bewley class of models or the one-sector model of the previous section, where more risk tends to decrease the risk-free rate. The reason for this new effect is that the technology in the public equity sector imposes a negative relation between the wage rate and the interest rate, namely the relation implied by the equation of the ratio of the two prices with the marginal rate of technical substitution between capital and labor. When an increase in idiosyncratic investment risk causes a reallocation of resources from private to public equity, thus reducing aggregate productivity and wages, the reduction in wages is necessarily associated with an increase in interest rates. In the Bewley class of models, the same negative relation between wages and interest rates is present, since all capital is public, but it works the other way round: higher labor-income risk leads to a lower interest rate and thereby to a higher capital-labor ratio and a higher wage rate. In the one-sector model of the previous sections, on the other hand, the negative relation between wages and interest rates was broken, because the interest rate is not equated to the marginal product of capital in private equity.

\subsection{Numerical results}

The new parameter that needs to be calibrated is $\mu$. Other things equal, $\mu$ determines the crosssectoral allocation of resources. As mentioned earlier, private and public equity each claim roughly half of aggregate production, employment, and wealth in the United States. Hence, for any given set of values for $(\sigma, \beta, \gamma, \theta, \alpha, \delta)$, I calibrate $\mu$ so that the implied steady-state shares of private and public equity in the aggregate capital stock are $50 \%$ each. The results are reported in Table 2. Calibrating $\mu$ to the shares of employment or output yields similar quantitative results.

In the benchmark calibration (first two rows of Table 2), the reduction in the saving rate is now $1.1-3.5$ percentage points as compared to $2.4-6.1$ percentage points without public equity. Similarly, the reduction in the capital stock is now $12 \%-33 \%$ as compared to $19 \%-45 \%$ without public equity. On the other hand, the reduction in the steady-state level of income is $7 \%-19 \%$ as compared to $9 \%-21 \%$ in the benchmark model. Hence, the impact of incomplete markets on aggregate savings is almost halved by the introduction of public equity, but the mitigating effect on aggregate income is only moderate. 


\begin{tabular}{|c|c|c|c|c|c|c|c|c|c|}
\hline$\sigma$ & $\gamma$ & $\theta$ & $\beta^{-1}-1$ & $\alpha$ & $\delta$ & $\begin{array}{c}\Delta \text { (Saving } \\
\text { Rate) }\end{array}$ & $\Delta(G D P)$ & $\begin{array}{c}\text { Interest } \\
\text { Rate }\end{array}$ & $\begin{array}{c}\text { Private } \\
\text { Premium }\end{array}$ \\
\hline $40 \%$ & \multirow{2}{*}{2} & \multirow{2}{*}{1} & \multirow{2}{*}{$5 \%$} & \multirow{2}{*}{$40 \%$} & \multirow{2}{*}{$5 \%$} & $-3.5 \%$ & $-19 \%$ & $4.69 \%$ & $2.99 \%$ \\
\hline $20 \%$ & & & & & & $-1.1 \%$ & $-7 \%$ & $4.89 \%$ & $0.91 \%$ \\
\hline $40 \%$ & \multirow{2}{*}{4} & \multirow{4}{*}{1} & \multirow{4}{*}{$5 \%$} & \multirow{4}{*}{$40 \%$} & \multirow{4}{*}{$5 \%$} & $-5.4 \%$ & $-29 \%$ & $4.53 \%$ & $5.22 \%$ \\
\hline $20 \%$ & & & & & & $-2.0 \%$ & $-12 \%$ & $4.80 \%$ & $1.72 \%$ \\
\hline $40 \%$ & \multirow{2}{*}{1} & & & & & $-2.0 \%$ & $-11 \%$ & $4.81 \%$ & $1.64 \%$ \\
\hline $20 \%$ & & & & & & $-0.6 \%$ & $-4 \%$ & $4.94 \%$ & $0.47 \%$ \\
\hline $40 \%$ & \multirow{4}{*}{2} & \multirow{2}{*}{2} & \multirow{4}{*}{$5 \%$} & \multirow{4}{*}{$40 \%$} & \multirow{4}{*}{$5 \%$} & $-3.7 \%$ & $-19 \%$ & $4.77 \%$ & $3.01 \%$ \\
\hline $20 \%$ & & & & & & $-1.3 \%$ & $-7 \%$ & $4.92 \%$ & $0.92 \%$ \\
\hline $40 \%$ & & \multirow{2}{*}{$1 / 2$} & & & & $-3.2 \%$ & $-18 \%$ & $4.55 \%$ & $2.95 \%$ \\
\hline $20 \%$ & & & & & & $-1.1 \%$ & $-6 \%$ & $4.83 \%$ & $0.91 \%$ \\
\hline $40 \%$ & \multirow{6}{*}{2} & \multirow{6}{*}{1} & \multirow{2}{*}{$5 \%$} & \multirow{2}{*}{$40 \%$} & \multirow{2}{*}{$10 \%$} & $-4.0 \%$ & $-11 \%$ & $4.80 \%$ & $2.37 \%$ \\
\hline $20 \%$ & & & & & & $-1.3 \%$ & $-4 \%$ & $4.94 \%$ & $0.69 \%$ \\
\hline $40 \%$ & & & \multirow{2}{*}{$10 \%$} & \multirow{2}{*}{$40 \%$} & \multirow{2}{*}{$5 \%$} & $-1.9 \%$ & $-17 \%$ & $9.49 \%$ & $3.87 \%$ \\
\hline $20 \%$ & & & & & & $-0.6 \%$ & $-6 \%$ & $9.82 \%$ & $1.15 \%$ \\
\hline $40 \%$ & & & \multirow{2}{*}{$5 \%$} & \multirow{2}{*}{$60 \%$} & \multirow{2}{*}{$5 \%$} & $-6.1 \%$ & $-46 \%$ & $4.22 \%$ & $4.76 \%$ \\
\hline $20 \%$ & & & & & & $-2.3 \%$ & $-20 \%$ & $4.69 \%$ & $1.52 \%$ \\
\hline
\end{tabular}

Table 2: The steady-state effects in the presence of public equity.

The reason the impact on output remains strong is that incomplete markets now distort also aggregate total factor productivity (the Solow residual). Indeed, private equity must have a higher mean return than public equity in order to compensate for the uninsured idiosyncratic risk. It follows that a high level of private risk reduces aggregate productivity by shifting resources away from private equity.

The rest of Table 2 performs a series of robustness checks like Table 1. Once again, the impact of incomplete markets is increased by a higher risk aversion, is little affected by the elasticity of intertemporal substitution, and remains significant across all specifications.

Finally, note that the equilibrium premium on private equity is significantly lower than what in the absence of public equity. In the benchmark calibration, for example, the private premium is $3 \%$ when $\sigma=40 \%$ (compared to $4.9 \%$ without public equity) and as low as $0.9 \%$ when $\sigma=20 \%$ (compared to 1.7\%). This is because the excess return required to compensate for the risk in private equity is significantly lower when only half of aggregate savings rather than the entire capital stock is in private equity. The model thus predicts that large effects on savings and income are consistent with small investment risks and low excess returns in private equity. 


\section{Transitional Dynamics and Amplification}

Since aggregate uncertainty is not allowed, I can not examine literally the business-cycle properties of the model. We can nevertheless get some guidance by studying the transitional dynamics.

To capture cyclical variation in aggregate productivity and the level of idiosyncratic risk, I modify the model as follows. Let $Z_{t}$ denote the aggregate labor productivity in period $t$; with a Cobb-Douglas production function, a change in $Z_{t}$ is, of course, isomorphic to a change in the total factor productivity of both sectors. I assume that $Z_{t}$ follows the deterministic analogue of an $A R(1)$ process:

$$
\ln Z_{t+1}=\rho \ln Z_{t}
$$

where $\rho \in[0,1)$ measures the persistence of productivity. I also allow for the level of idiosyncratic risk to vary with the state of the economy:

$$
\sigma_{t} \equiv \operatorname{Var}_{t}\left(\ln A_{t+1}^{i}\right)^{1 / 2}=\sigma\left[1-\eta \ln Z_{t}\right]
$$

where $\sigma \geq 0$ and $\eta \geq 0$ parameterize, respectively, the steady-state level and the cyclical elasticity of idiosyncratic risk. I can then mimic a "recession" with an once-and-for-all reduction in $Z_{0}$ starting from the steady state.

Thanks to the simple closed-form recursive structure of the general equilibrium, it is easy to compute the response of the economy to such a shock - or, more generally, the transitional dynamics from any given initial conditions. Assuming $\theta=1$ (benchmark calibration) further simplifies the equilibrium recursion by implying $s_{t}=\beta .^{15}$

Lemma 3 Suppose $\theta=1$ and $\left(Z_{t}, \sigma_{t}\right)$ satisfy (38)-(39). There is a unique mapping $\Omega: \mathbb{R}^{4} \rightarrow \mathbb{R}^{8}$ such that, for all $t \geq 0$,

$$
\left(\left(Z_{t+1}, K_{t+1}, X_{t+1}, H_{t}\right),\left(C_{t}, Y_{t}, \omega_{t}, R_{t}\right)\right)=\Omega\left(Z_{t}, K_{t}, X_{t}, H_{t-1}\right)
$$

For any given $\left(Z_{0}, K_{0}, X_{0}, H_{-1}\right)$, the whole path is computed simply by iterating $\boldsymbol{\Omega}$. Since $\left(Z_{0}, K_{0}, X_{0}\right)$ are historically given, one only needs to find the equilibrium value for $H_{-1}$. Starting with an arbitrary guess for $H_{-1}$, iterating $\Omega$ to compute the implied $\left\{\omega_{t}, R_{t}\right\}_{t=0}^{T}$ for $T$ large enough, and letting $H_{-1}^{\prime}=\sum_{t=1}^{T} \omega_{t} /\left(R_{1} \ldots R_{t-1}\right)$, gives a mapping from $H_{-1}$ to $H_{-1}^{\prime}$. Iterating this mapping till $H_{-1}^{\prime} \approx H_{-1}$ gives the equilibrium. ${ }^{16}$

In the rest of this section, I first discuss how idiosyncratic investment risk may introduce a novel amplification mechanism. I then use the above algorithm to simulate the transitional dynamics and quantify the amplification.

\footnotetext{
${ }^{15}$ If, instead, $\theta \neq 1$, the "state vector" $\left(Z_{t+1}, K_{t+1}, X_{t+1}, H_{t}\right)$ must be expanded to include $s_{t}$.

${ }^{16}$ Although this is not a contraction mapping, I obtained a fixed point for all the simulations reported below.
} 


\subsection{Some partial insights}

The amplification originates in two distinct, yet complementary sources. First, cyclical variation in the level of uninsurable idiosyncratic risk generates cyclical variation in investment demand and aggregate productivity. Second, the dependence of risk taking on future income introduces a dynamic macroeconomic complementarity. I explain the two amplification channels below.

First, consider the role of exogenous cyclical variation in $\sigma_{t}$. As the economy enters a recession (that is, after a negative shock in $Z_{0}$ ), the level $\sigma_{t}$ of uninsurable investment risk increases, implying a reduction in the willingness to invest in private equity. That is, the demand for investment is low during a recession, not only because interest rates are high - the standard reason in the completemarkets neoclassical model - but also because private risk premia are high. Moreover, as resources are diverted away from private equity towards public equity, an endogenous reduction in aggregate productivity takes place. In other words, the Solow residual itself is amplified.

Second, consider the role of the endogenous cyclical variation in the willingness to take risk. To gain some insight, ignore for a moment the presence of public equity and the equilibrium variation in $R, s$, or $\phi$. Conditions (19) and (20) then reduce to

$$
\begin{aligned}
K_{t+1} & =s \phi\left[f\left(K_{t}\right)+H_{t}\right], \\
H_{t} & =\sum_{j=1}^{\infty} R^{-j} \omega\left(K_{t+j}\right) .
\end{aligned}
$$

On one hand, (40) implies that, other things equal, $K_{t+1}$ increases with either $K_{t}$ or $H_{t}$ and therefore the path of capital $\left\{K_{t+1}, K_{t+2}, \ldots\right\}$ increases with the path of human wealth $\left\{H_{t}, H_{t+1}, \ldots\right\}$. This effect reflects a decision-theoretic property: the dependence of individual risk taking on wealth. On the other hand, (41) implies that $\left\{H_{t+1}, H_{t+2}, \ldots\right\}$ increases with $\left\{K_{t+1}, K_{t+2}, \ldots\right\}$. This feedback reflects a general-equilibrium effect: the dependence of individual labor income and wealth on aggregate capital. The combination of these two effects gives rise to a dynamic macroeconomic complementarity: the anticipation of low income tomorrow leads every agent to invest less today, which in turn implies lower aggregate income tomorrow. ${ }^{17}$

Three remarks are worth making about this complementarity. First, it introduces a short of "Keynesian accelerator" in an RBC economy: investment demand depends directly on income and wealth. Second, it derives from two simple ingredients: that private investment is subject to uninsured idiosyncratic risk and that risk taking is sensitive to anticipated income. ${ }^{18}$ Third, and most

\footnotetext{
${ }^{17}$ The paper thus also contributes to the literature on macroeconomic complementarities (e.g., Benhabib and Farmer, 1994; Cooper, 2000).

${ }^{18}$ This also explains why this complementarity is novel in the literature: the first ingredient is absent in Bewley models (e.g., Aiyagari, 1994, Krusell and Smith, 1998), whereas the second one in abscent in $A K$ models, such as Obstfeld (1994) and Krebs (2003), or credit models with risk-neutral entrepreneurs, such as Bernanke and Gertler (1989) and Kiyotaki and Moore (1997), as well as the CARA-normal economy of Angeletos and Calvet (2003, 2004).
} 
importantly, this is only part of the story: although this complementarity contributes to amplifying the transitional dynamics, there may be other counteracting effects in general equilibrium.

To obtain a more complete picture and make a first pass at the quantitative potential of the amplification effects discussed above, I next simulate the response of the economy to an unanticipated shock in aggregate productivity $Z_{0}$.

\subsection{A numerical example}

As mentioned earlier, reliable measures of idiosyncratic investment risk are not available. There are various indications that the these risks are highly cyclical - proxies such as bankruptcy rates, firm-exit rates, and firm-specific volatility in publicly traded firms vary a lot over the business cycle - but there is no hard evidence on which I could base the calibration of $\eta$, the cyclical sensitivity of idiosyncratic investment risk. In lack of a better alternative, I make a plausible, yet random, guess: I calibrate $\eta$ so that a $2 \%$ reduction in output below its steady-state value is associated with a $5 \%$ increase in the standard deviation of investment returns. For the rest of the parameters, I use the benchmark calibration $\left(\gamma=2, \theta=1,1-\beta^{-1}=5 \%, \alpha=40 \%, \delta=5 \%\right.$ ), with $\sigma=20 \%$ and $\mu$ such that $50 \%$ of capital is private equity, and finally with $\rho=95 \%$, which roughly matches the autocorrelation of the Solow residual in U.S. data.

Figure 1 illustrates the response of the economy to a negative productivity shock. The initial values are $\ln Z_{0}=-1 \% /(1-\alpha), K_{0}=K_{\infty}$ and $X_{0}=X_{\infty}$, meaning a $1 \%$ exogenous reduction in total factor productivity starting from the steady state. The solid lines represent the response of the economy under incomplete markets, whereas the dashes lines correspond to complete markets (that is, to the standard neoclassical growth model). The amplification effect is quite strong: the impact of the exogenous shock on aggregate output, consumption, and investment is, respectively, $63 \%, 92 \%$, and $53 \%$ higher than the impact of the shock under complete markets. ${ }^{19}$ Importantly, note how the amplification shows up in aggregate productivity: the reallocation of resources away from private equity contributes $42 \%$ of the overall reduction in the Solow residual.

These results, however, do not distinguish whether the main source of amplification is the cyclical variation in risk or the macroeconomic complementarity discussed earlier. To isolate the role of the complementarity, Figure 2 repeats the same exercise as Figure 1 setting $\eta=0$. The impact of the shock on all macroeconomic variables under incomplete markets is now only slightly larger than that under complete markets. ${ }^{20}$ The reason the amplification effect of the complementarity is weak

\footnotetext{
${ }^{19}$ For each variable $X$, I compute the "multiplier" of incomplete markets by taking the maximal value of the ratio $\hat{X}_{t}^{\text {inco }} / \hat{X}_{t}^{\text {com }}$ over the first 4 periods, where $\hat{X}_{t}^{\text {inco }}=\left(X_{t}-X_{\infty}\right) / X_{\infty}$ denotes the period- $t$ percentage change relative to the steady-state value under incomplete markets, and $\hat{X}_{t}^{c o m}$ the corresponding change under complete markets. (Taking the average instead of the maximal ratio gives similar results.) The numbers reported in the text are the corresponding multipliers minus 1 .

${ }^{20}$ For brevity, only the responses of output and the Solow residual are depicted in Figure 2; the amplification of
} 

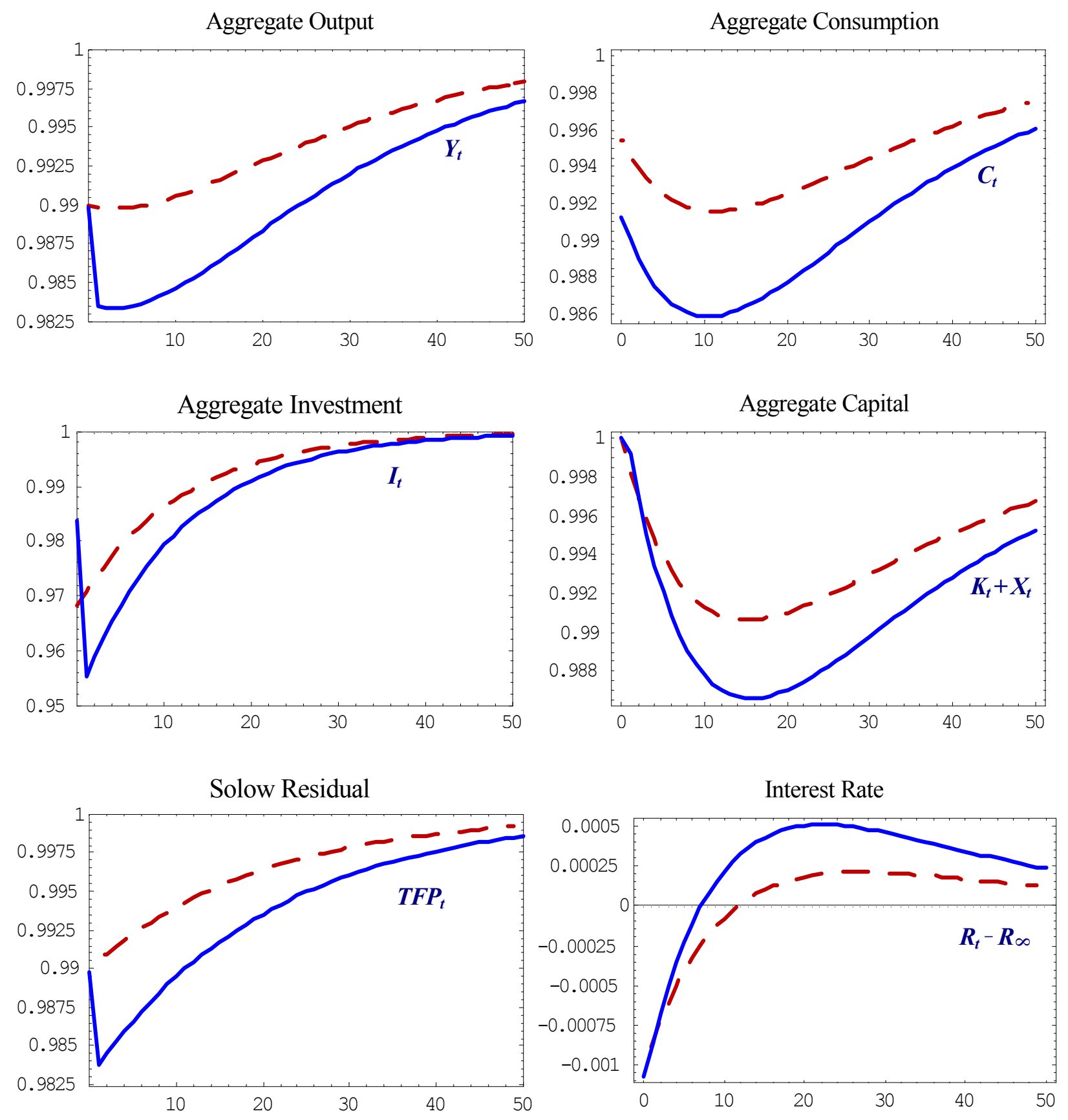

Figure 1: The response of the economy to a negative $1 \%$ shock in aggregate productivity. Solid lines for incomplete markets with cyclical idiosyncratic risk; dashed lines for complete markets. All variables normalized by their respective steady-state levels. 
is the presence of another offsetting general-equilibrium effect which the earlier intuitive discussion overlooked: the reduction in real interest rates during the recession counteracts the reduction in expected future wage rates and thereby mitigates the reduction in the demand for private equity. In other words, the "Keynesian accelerator" is here offset by a "neoclassical" price effect. ${ }^{21}$
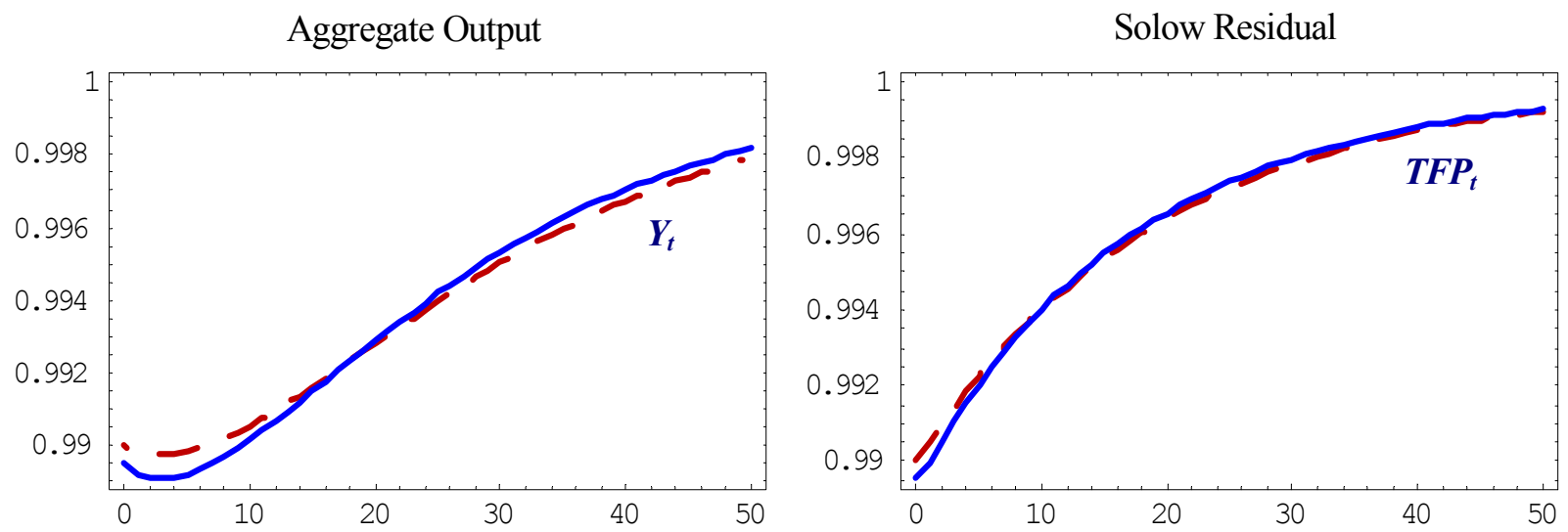

Figure 2: The response of the economy with acyclical idiosyncratic risk.

To recap, the complementarity may be of theoretical interest on its own - for it is likely to extend to a larger class of models where agents face idiosyncratic investment risk - but it fails to generate strong amplification in the context of the present model. In contrast, cyclical variation in idiosyncratic risk appears to have a more significant quantitative potential.

\section{Concluding Remarks}

This paper made a first attempt in characterizing and quantifying the macroeconomic effects of idiosyncratic investment risks. The merit but also the limitation of the analysis was its proximity to the standard neoclassical growth model: the only modification was the introduction of uninsurable risks in private investment.

An important result in the Ramsey literature is that the optimal tax on capital is typically zero under complete markets (Chamley, 1986; Judd, 1985; Atkeson, Chari and Kehoe, 1999) and positive in Bewley economies (Aiyagari, 1995). A natural question is whether idiosyncratic investment risks, by leading to low savings, also raise the possibility that an investment subsidy is optimal in some cases. Another question is the properties of optimal taxes along the transitional dynamics: does other macroeconomic variables is similarly small.

${ }^{21}$ Note, however, that this offsetting effect would be abscent in an open-economy version of the model where the risk-free rate is exogenously fixed. Indeed, in that case domestic investment simply tracks aggregate productivity in the absence of idiosyncratic investment risks, whereas it also depends on domestic wealth under incomplete markets. 
the amplification discussed above open the door to a stabilization role for policy? The tractability of the model may prove useful in answering these questions. ${ }^{22}$

Tractability, however, did not come for free. I assumed away aggregate uncertainty, occupational choice, labor supply, and labor-income risk. I also ignored the endogeneity of financial contracts, which may be important for both the positive and the normative implications of the analysis. Furthermore, the model lacked any mean-reverting force in individual wealth dynamics, such as the one introduced by labor-income risk (e.g., Aiyagari, 1994) or diminishing returns in privately-held businesses (e.g., Banerjee and Newman, 1993; Caggeti and De Nardi, 2003), and therefore had no interesting implications for the wealth distribution. Extending the analysis in these directions is essential for a better quantitative assessment of the macroeconomic effects of private equity and idiosyncratic investment risk - this paper hopes to have provided a useful benchmark.

\section{Appendix: Proofs}

Proof of Lemma 1. By the linear homogeneity of $F(K, L, A)$ in $(K, L)$,

$$
\frac{\pi_{t}^{i}}{k_{t}^{i}}=F\left(1, \frac{n_{t}^{i}}{k_{t}^{i}}, A_{t}^{i}\right)-\omega_{t} \frac{n_{t}^{i}}{k_{t}^{i}}
$$

Since $k_{t}^{i}$ and $A_{t}^{i}$ are known when $n_{t}^{i}$ is chosen, the optimal $n_{t}^{i} / k_{t}^{i}$ maximizes (42) for any $A_{t}^{i}$, which gives (7). By definition of $n(\cdot)$ and $r(\cdot), F_{L}(1, n(A, \omega), A) \equiv \omega$ and $r(A, \omega) \equiv F(1, n(A, \omega), A)-$ $\omega n(A, \omega)$. Hence, $F(K, L, 0)=0$ implies $n(0, \cdot)=r(0, \cdot)=0$, whereas $n(A, \cdot)>0$ and $r(A, \cdot)>0$ for $A>0$. Applying the implicit function theorem and using $F_{L}>0, F_{L L}<0, F_{A}>0$, and $F_{L A}>0$, we infer $n_{\omega}<0<n_{A}$ and $r_{\omega}<0<r_{A}$. Finally, the Inada conditions imply, for any $A>0, \lim _{\omega \rightarrow 0} n(A, \omega)=\lim _{\omega \rightarrow 0} r(A, \omega)=\infty$ and $\lim _{\omega \rightarrow \infty} n(A, \omega)=\lim _{\omega \rightarrow \infty} r(A, \omega)=0$.

Proof of Lemma 2. For notational simplicity, I drop the superscript $i$ and use $r_{t+1}$ as a short-cut for $r\left(A_{t+1}, \omega_{t+1}\right)$. I propose the following solution for the value function and the policy rules:

$$
V(w ; t)=a_{t} \frac{\left(w+h_{t}\right)^{1-1 / \theta}}{1-1 / \theta}, \quad c(w ; t)=\left(1-s_{t}\right)\left(w+h_{t}\right), \quad k(w ; t)=\phi_{t} s_{t}\left(w+h_{t}\right)
$$

where $a_{t}, s_{t}$, and $\phi_{t}$ are (possibly time-varying but non-stochastic) coefficients to be determined. From the budget constraint and (43), we then infer $b(w ; t)=\left(1-\phi_{t}\right) s_{t}\left(w+h_{t}\right)-h_{t}$. From (2) and

\footnotetext{
${ }^{22}$ The answers to these questions are non-trivial for at least three reasons: unlike Aiyagari (1995), a comparison of the steady-state level of capital with its first-best value may be misleading; a tax on capital may still be desirable from an insurance perspective; amplification does not necessarily mean inefficiency.
} 
(43), the certainty equivalent of the value of wealth is

$$
\mathbb{C E}_{t}\left[U^{-1} V_{t+1}\left(w_{t+1}\right)\right]=\Upsilon^{-1}\left\{\mathbb{E}_{t}\left[\Upsilon U^{-1} V_{t+1}\left(w_{t+1}\right)\right]\right\}=a_{t+1}^{1 /(1-1 / \theta)}\left[\mathbb{E}_{t}\left(w_{t+1}+h_{t+1}\right)^{1-\gamma}\right]^{1 /(1-\gamma)} .
$$

Hence, the first-order conditions with respect to $k_{t+1}$ and $b_{t+1}$ give:

$$
\begin{aligned}
& \left(c_{t}\right)^{-1 / \theta}=\beta a_{t+1}^{1-1 / \theta} \cdot\left[\mathbb{E}_{t}\left(w_{t+1}+h_{t+1}\right)^{1-\gamma}\right]^{(\gamma-1 / \theta) /(1-\gamma)} \cdot \mathbb{E}_{t}\left[\left(w_{t+1}+h_{t+1}\right)^{-\gamma} r_{t+1}\right], \\
& \left(c_{t}\right)^{-1 / \theta}=\beta a_{t+1}^{1-1 / \theta} \cdot\left[\mathbb{E}_{t}\left(w_{t+1}^{i}+h_{t+1}\right)^{1-\gamma}\right]^{(\gamma-1 / \theta) /(1-\gamma)} \cdot \mathbb{E}_{t}\left[\left(w_{t+1}+h_{t+1}\right)^{-\gamma} R_{t+1}\right] .
\end{aligned}
$$

Combining the two conditions, and using

$$
w_{t+1}=r_{t+1} k_{t+1}+R_{t+1} b_{t+1}+\omega_{t}=\left[\phi_{t} r_{t+1}+\left(1-\phi_{t}\right) R_{t+1}\right] s_{t}\left(w_{t}+h_{t}\right)-h_{t+1},
$$

we get $\mathbb{E}_{t}\left\{\left[R_{t+1}+\phi_{t}\left(r_{t+1}-R_{t+1}\right)\right]^{-\gamma}\left(r_{t+1}-R_{t+1}\right)\right\}=0$, or equivalently $\phi_{t}=\phi\left(\omega_{t+1}, R_{t+1}\right)$. Next, the envelope condition, $V^{\prime}\left(w_{t} ; t\right)=U^{\prime}\left(c_{t}\right)$, or equivalently $a_{t}^{1-1 / \theta}\left(w_{t}+h_{t}\right)^{-1 / \theta}=\left(c_{t}\right)^{-1 / \theta}$, along with $c_{t}=\left(1-s_{t}\right)\left(w_{t}+h_{t}\right)$ from (43), implies

$$
a_{t}^{1-1 / \theta}=\left(1-s_{t}\right)^{-1 / \theta}
$$

Multiplying (44) and (45) with $\phi_{t}$ and $\left(1-\phi_{t}\right)$, respectively, summing up, substituting $w_{t+1}$ in the resulting relation from (46), and rearranging, gives the saving rate in recursive form:

$$
\left(1-s_{t}\right)^{-1}=1+\beta^{\theta} \rho_{t}^{\theta-1}\left(1-s_{t+1}\right)^{-1}
$$

where $\rho_{t}=\rho\left(\omega_{t+1}, R_{t+1}\right)$. For any $\left\{\omega_{t}, R_{t}\right\}_{t=0}^{\infty}$ that is part of an equilibrium, the infinite sum $\sum_{s=t}^{\infty} \prod_{\tau=t}^{s}\left[\beta^{\theta} \rho_{\tau}^{\theta-1}\right]$ is finite. Forward iteration of (48) thus yields (13), with $s_{t} \in(0,1)$. Using (43), we then verify that $c_{t}>0, k_{t+1}>0$, and $b_{t+1}>-h_{t}$. Finally, we verify that (43) solves the Bellman equation: substituting (43) into (9) gives

$$
\frac{\left[a_{t}\left(w_{t}+h_{t}\right)\right]^{1-1 / \theta}}{1-1 / \theta}=\frac{\left[\left(1-s_{t}\right)\left(w_{t}+h_{t}\right)\right]^{1-1 / \theta}}{1-1 / \theta}+\beta \frac{\left\{a_{t+1}\left[\mathbb{E}_{t}\left(w_{t+1}+h_{t+1}\right)^{1-\gamma}\right]^{1 /(1-\gamma)}\right\}^{1-1 / \theta}}{1-1 / \theta}
$$

dividing both sides by $\left(w_{t}+h_{t}\right)^{1-1 / \theta} /(1-1 / \theta)$ and using (46) and (48), the above reduces to $a_{t}^{1-1 / \theta}=\left(1-s_{t}\right)^{-1 / \theta}\left[\left(1-s_{t}\right)+a_{t+1}^{1-1 / \theta}\left(1-s_{t+1}\right)^{1 / \theta} s_{t}\right]$, which is satisfied by $(47)$.

Proof of Condition (16). To simplify notation, let $r_{t+1}^{i}=r\left(A_{t+1}^{i}, \omega_{t+1}\right), \bar{r}_{t+1}=\mathbb{E}_{t} r_{t+1}^{i}$, and $\sigma_{t+1}^{2}=\operatorname{Var}_{t}\left[\ln r_{t+1}^{i}\right]$. A second-order Taylor approximation for $\ln \rho_{t}$ around $\sigma_{t}=0$ gives

$$
\ln \rho_{t} \approx \phi_{t} \mathbb{E}_{t}\left[\ln r_{t+1}^{i}\right]+\left(1-\phi_{t}\right) \ln R_{t+1}+\frac{1}{2} \phi_{t}\left(1-\phi_{t}\right) \sigma_{t+1}^{2}-\frac{1-\gamma}{2} \phi_{t}^{2} \sigma_{t+1}^{2}
$$

Since $\phi_{t}$ maximizes $\rho_{t}$, the above also implies

$$
\phi_{t} \approx \frac{\mathbb{E}_{t} \ln r_{t+1}^{i}-\ln R_{t+1}+\sigma_{t+1}^{2} / 2}{\gamma \sigma_{t+1}^{2}} .
$$


(These two equations are the analogues of (2.24) and (2.25) in Chapter 2 of Campbell and Viceira (2002); see there for a detailed derivation.) Combining the two conditions above and using $\mathbb{E}_{t} \ln r_{t+1}^{i} \approx \ln \mathbb{E}_{t} r_{t+1}^{i}-\operatorname{Var}_{t}\left[\ln r_{t+1}^{i}\right] / 2=\ln \bar{r}_{t+1}-\sigma_{t+1}^{2} / 2$ gives (16).

Proof of Proposition 1. Note that $\phi_{t}$ and $s_{t}$ are identical across agents. Aggregating the conditions in Lemma 2 over all $i$ and using the facts that $A_{t}^{i}$ and $k_{t}^{i}$ are independent and that $\Pi_{t}+\omega_{t}=\bar{r}\left(\omega_{t}\right) K_{t}+\omega_{t}=f\left(K_{t}\right)=Y_{t}$, we infer

$$
\begin{aligned}
W_{t} & =\Pi_{t}+R B_{t}+\omega_{t}=f\left(K_{t}\right)+R B_{t} \\
C_{t} & =\left(1-s_{t}\right)\left(W_{t}+H_{t}\right) \\
K_{t+1} & =s_{t} \phi_{t}\left(W_{t}+H_{t}\right) \\
B_{t+1} & =s_{t}\left(1-\phi_{t}\right)\left(W_{t}+H_{t}\right)-H_{t}
\end{aligned}
$$

where $B_{t}=\int b_{t}^{i} d i$. The bond market clears if and only if $B_{t}=0$ and therefore $W_{t}=f\left(K_{t}\right)=Y_{t}$. Along with (52) and (53), this immediately gives (18) and (19). Next, adding up (52)-(54) gives the resource constraint (17), whereas (20) follows directly from (5). Finally, the labor market clears if and only if $1=\int n_{t}^{i}=\bar{n}\left(\omega_{t}\right) K_{t}$, which gives $(21)$.

Proof of Proposition 2. Evaluating (51)-(54) [equivalently, (17)-(21)] in the steady state and combining, we get $K+H=s(W+H)=s[\bar{r}(\omega) K+R H]=s[\phi \bar{r}(\omega)+(1-\phi) R](K+H)$, or equivalently

$$
1=s[\phi \bar{r}(\omega)+(1-\phi) R]
$$

which is simply the stationarity condition for aggregate wealth. Substituting $s=\beta^{\theta} \rho^{\theta-1}$ into the above gives condition (23) in the Proposition. Next, by (22), (53), (54), and the property that, under A1, $\bar{r}(\omega)=F_{K}(K, 1,1)=f^{\prime}(K)$ and $\omega=f(K)-f^{\prime}(K) K$, we have

$$
\frac{H}{K}=\frac{1-\phi}{\phi} \quad \text { and } \quad H=\frac{\omega}{R-1}=\frac{f(K)-f^{\prime}(K) K}{R-1} .
$$

Combining gives condition (24) in the Proposition.

Proof of Condition (25). Let $\hat{\mu} \equiv \ln \bar{r}(\omega)-\ln R=\ln f^{\prime}(K)-\ln R$. Taking logarithms of (36) we get

$$
\theta \ln (\beta R)+(\theta-1)(\ln \rho-\ln R)+\ln \left(\phi e^{\hat{\mu}}+1-\phi\right)=0 .
$$

Approximating $\ln \left(\phi e^{\hat{\mu}}+1-\phi\right)$ around $\hat{\mu}=0$ gives $\ln \left(\phi e^{\hat{\mu}}+1-\phi\right) \approx \phi \hat{\mu}$ and therefore

$$
\theta \ln (\beta R)+(\theta-1)(\ln \rho-\ln R)+\phi \hat{\mu} \approx 0
$$

Substituting $\phi \approx \hat{\mu} /\left(\gamma \sigma^{2}\right)$ and $\rho \approx R \exp \left[\hat{\mu}^{2} /\left(2 \gamma \sigma^{2}\right)\right]$ into the above, we conclude that $\hat{\mu}$ solves

$$
0 \approx \theta \ln (\beta R)+\frac{\theta+1}{2} \frac{\hat{\mu}^{2}}{\gamma \sigma^{2}} .
$$


Note that the above has two real solutions, but only one is positive, and this one gives the equilibrium premium. Substituting this solution into $\hat{\mu}=\ln f^{\prime}(K)-\ln R$ gives (25).

Proof of Proposition 3. By $(24), \phi \in(0,1)$. For that to be true, it must be that $f^{\prime}(K)>R$, or otherwise the bond would dominate private equity. By risk aversion, then, $R<\rho<\phi f^{\prime}(K)+$ $(1-\phi) R$, which together with $(23)$ gives also $\rho<1 / \beta$. Combining, we have

$$
R<\rho<\phi f^{\prime}(K)+(1-\phi) R<f^{\prime}(K) \text { and } \quad R<\rho<1 / \beta .
$$

Next, taking logarithms of (23) and rearranging gives

$$
\theta \log \left[\beta f^{\prime}(K)\right]=-\log \left[\phi+(1-\phi) R / f^{\prime}(K)\right]-(\theta-1) \log \left[\rho / f^{\prime}(K)\right] .
$$

It follows that $\beta f^{\prime}(K)>1$ if and only if $\theta>\underline{\theta}$ where

$$
\underline{\theta}=1-\frac{\log \left[\phi+(1-\phi) R / f^{\prime}(K)\right]}{\log \left[\rho / f^{\prime}(K)\right]} .
$$

Note that $\underline{\theta}$ above is expressed in terms of endogenous variables, but (55) ensures that $\underline{\theta}<1$. Next, consider the limit as $\sigma \rightarrow 0$. Letting stars indicate the steady-state values under complete markets, we have that $R, \rho, f^{\prime}(K) \rightarrow R^{*}=\beta^{-1}, K \rightarrow K^{*}=f^{-1}(1 / \beta)$, and $\phi \rightarrow \phi^{*}$, where

$$
\frac{1-\phi^{*}}{\phi^{*}}=\frac{f\left(K^{*}\right)-f^{\prime}\left(K^{*}\right) K^{*}}{\left(R^{*}-1\right) K^{*}}=\frac{f\left(K^{*}\right) / K^{*}-R^{*}}{R^{*}-1} \in(0,1) .
$$

Thus, using L'Hopital's rule in (56), we have that, as $\sigma \rightarrow 0$,

$$
\underline{\theta} \rightarrow 1-\left(1-\phi^{*}\right)=\phi^{*} .
$$

Finally, letting $\kappa$ and $\alpha$ denote, respectively, the capital-output ratio and the income share of capital (that is, $\kappa=K^{*} / \hat{f}\left(K^{*}\right)$ and $\alpha=\hat{f}^{\prime}\left(K^{*}\right) K^{*} / \hat{f}\left(K^{*}\right)$, where $\left.\hat{f}(K)=f(K)-(1-\delta) K=K^{\alpha}\right)$, we get by (57) that

$$
\phi^{*}=\frac{R^{*}-1}{f\left(K^{*}\right) / K^{*}-1}=\frac{\alpha}{1+\delta \kappa} \leq \alpha
$$

which completes the proof.

Proof of Proposition 4. The budget constraint of household $i$ in period $t$ reduces

$$
c_{t}^{i}+k_{t+1}^{i}+\left(x_{t+1}^{i}+b_{t+1}^{i}\right) \leq w_{t}^{i}=r\left(A_{t}^{i}, \omega_{t}\right) k_{t}^{i}+R_{t}\left(x_{t}^{i}+b_{t}^{i}\right)+\omega_{t} .
$$

Hence, Lemma 2 continues to apply provided we replace $b$ with $x+b$; that is,

$$
\begin{gathered}
c_{t}^{i}=\left(1-s_{t}\right)\left(w_{t}^{i}+h_{t}\right) \\
k_{t+1}^{i}=s_{t} \phi_{t}\left(w_{t}^{i}+h_{t}\right) \\
x_{t+1}^{i}+b_{t+1}^{i}=s_{t}\left(1-\phi_{t}\right)\left(w_{t}^{i}+h_{t}\right)-h_{t}
\end{gathered}
$$


where $\phi_{t}, \rho_{t}$, and $s_{t}$ are defined again as in Lemma 2. Conditions (27), (28), (31), and (33) then follow from aggregating across agents and using the bond market clearing condition, $\int b_{t+1}^{i}=0$, like in Proposition 1. Finally, (30) follows from profit maximization in the public-equity sector and (32) from labor market clearing.

Proof of Proposition 5. We first prove that $\rho(\omega, R)=\varrho R$ and $\phi(\omega, R)=\varphi$, where $\varrho$ and $\varphi$ are given by (34)-(35). Under A1, $n(A, \omega)=A \bar{n}(\omega), r(A, \omega)=A \bar{r}(\omega)$, and $\bar{r}(\omega)=F_{K}(1, \bar{n}(\omega), 1)$. It follows that

$$
\begin{aligned}
& \phi(\omega, R)=\arg \max _{\varphi}\left\{\int\left[\varphi A F_{K}(1, \bar{n}(\omega), 1)+(1-\varphi) R\right]^{1-\gamma} \psi(A) d A\right\}^{1 /(1-\gamma)} \\
& \rho(\omega, R)=\max _{\varphi}\left\{\int\left[\varphi A F_{K}(1, \bar{n}(\omega), 1)+(1-\varphi) R\right]^{1-\gamma} \psi(A) d A\right\}^{1 /(1-\gamma)}
\end{aligned}
$$

Under A2, on the other hand, $R=G_{K}(1, l(\omega))=F_{K}(1, \bar{n}(\omega), 1) / \mu$. Combining gives the result. We now prove the proposition.

(a) Like in the one-sector case, stationarity of aggregate wealth requires $s[\varphi \bar{r}(\omega)+(1-\varphi) R]=$ 1 , where $s=\beta^{\theta} \rho^{\theta-1}$. Using $R=R(\omega)$ and $\bar{r}(\omega)=\mu R(\omega)$, we have $\rho=\varrho R$ and $[\varphi \bar{r}(\omega)+(1-\varphi) R]=$ $(\varphi \mu+1-\varphi) R$, and therefore the stationarity condition reduces to (36). This together with $R=R(\omega)$ gives a unique $R$ and a unique $\omega$. Next, in steady state, $K=\varphi s[W+H]$ and $X+H=(1-\varphi)[W+H]$, and therefore $(X+H) / K=(1-\phi) / \phi$. On the other hand, the clearing condition for the labor market gives $\bar{n}(\omega) K+l(\omega) X=1$. Using $\bar{n}(\omega)=\mu l(\omega)$, and solving the above two conditions for $K$ and $X$, we get

$$
K=\frac{\varphi[1+l(\omega) H]}{(\varphi \mu+1-\varphi) l(\omega)} \quad \text { and } \quad X=\frac{1-\varphi-\varphi \mu l(\omega) H}{(\varphi \mu+1-\varphi) l(\omega)}
$$

or equivalently (37). This completes the characterization of the steady state. Uniqueness is obvious. As for existence, note that any $\mu>1$ implies $\varphi>0$ and therefore $K>0$ necessarily. On the other hand, $X>0$ if and only if $\varphi$ is sufficiently small, which is the case as long as $\sigma$ is sufficiently large.

(b) Since $R^{\prime}(\omega)<0, \omega$ decreases with $\sigma$ if and only if $R$ increases with $\sigma$. From condition (36),

$$
\frac{d \ln R}{d \sigma}=-\frac{1}{\theta}\left[\frac{\mu-1}{\varphi \mu+1-\varphi} \frac{d \ln \varphi}{d \sigma}+(\theta-1) \frac{d \ln \varrho}{d \sigma}\right] .
$$

It follows that $d R / d \sigma>0$, and therefore $d \omega / d \sigma<0$, if and only if $\theta>\underline{\theta}$, where

$$
\underline{\theta}=1-\frac{\mu-1}{\varphi \mu+1-\varphi} \frac{d \ln \varphi / d \sigma}{d \ln \varrho / d \sigma}
$$

An increase in $\sigma$ unambiguously lowers $\varphi$ and $\varrho$, which immediately proves $\underline{\theta}<1$. Next, since $l^{\prime}(\omega)<0$ and $R^{\prime}(\omega)<0$, from (37) we infer that $K$ is increasing in $\omega$ and decreasing in $\varphi$, and $X$ is increasing in $\varphi$ but (possibly) non-monotonic in $\omega$. Since

$$
K+X=1 / l(\omega)-(\mu-1) \frac{1 / l(\omega)+\omega /(R-1)}{\mu+1 / \varphi-1}=1 / l(\omega)-(\mu-1) K,
$$


aggregate capital $K+X$ is necessarily increasing in $\varphi$ but non-monotonic in $\omega$ and therefore non-monotonic in $\sigma$ as well. Finally, aggregate output is $Y=F(1, \bar{n}(\omega), \bar{A}) K+G(1, l(\omega)) X$. Using $\bar{n}(\omega)=\mu l(\omega)$ and $F(K / \mu, N, A)=F(K, N, A / \mu)=G(K, N)$, we have $F(1, \bar{n}(\omega), 1)=$ $F(1, \mu l(\omega), 1)=G(1, l(\omega)) \mu$ and therefore $Y=G(1, l(\omega))[\mu K+X]$, which together with (37) gives $Y=G(1 / l(\omega), 1)$. Output thus increases with $\omega$, reflecting the fact that $\omega$ increases if and only if resources are shifted from less productive public equity to more productive private equity. By implication, $Y /(K+X)$ and $C=Y-(K+X)$ also increase with $\omega$ and decrease with $\varphi$. We conclude that $\theta>\underline{\theta}$ suffices for an increase in $\sigma$ to raise $R$ and reduce $\omega, K, Y, Y /(N+L)$, and $Y /(K+X)$.

Proof of Lemma 3. Let $\omega_{t}$ denote the wage rate per effective unit of labor and take a given $\left(Z_{t}, K_{t}, X_{t}, H_{t-1}\right)$. The labor-market clearing condition, $\bar{n}\left(\omega_{t}\right) K_{t}+l\left(\omega_{t}\right) X_{t}=Z_{t}$, gives a unique $\omega_{t}$. Next, let $R_{t}=R\left(\omega_{t}\right), H_{t}=R\left(\omega_{t}\right) H_{t-1}-\omega_{t} Z_{t}$, and $Y_{t}=f\left(\omega_{t}\right) K_{t}+g\left(\omega_{t}\right) X_{t}$, where $f\left(\omega_{t}\right) \equiv$ $F\left(1, \bar{n}\left(\omega_{t}\right), 1\right)$ and $g\left(\omega_{t}\right) \equiv G\left(1, l\left(\omega_{t}\right)\right)$. Next, denote with $\psi_{t}(A)$ the p.d.f. for the lognormal distribution $\ln A \sim \mathcal{N}\left(-\sigma_{t}^{2} / 2, \sigma_{t}^{2}\right)$, where $\sigma_{t}=\sigma\left[1-\eta \ln Z_{t}\right]$, and let $\phi_{t}=\arg \max _{\varphi}\left\{\int(\varphi A \mu+1-\mu)^{1-\gamma}\right.$ $\left.\psi_{t}(A) d A\right\}^{1 /(1-\gamma)} \approx \mu /\left(\gamma \sigma_{t}^{2}\right)$. Finally, let $C_{t}=(1-\beta)\left[Y_{t}+H_{t}\right], K_{t+1}=\phi_{t} \beta\left[Y_{t}+H_{t}\right], X_{t+1}=$ $\left(1-\phi_{t}\right) \beta\left[Y_{t}+H_{t}\right]-H_{t}$, and $Z_{t+1}=Z_{t}^{\rho}$, which completes the construction of $\left(Z_{t+1}, K_{t+1}, X_{t+1}, H_{t}\right)$ and $\left(C_{t}, Y_{t}, \omega_{t}, R_{t}\right)$.

\section{References}

[1] Aiyagari, S. R. (1994), "Uninsured Idiosyncratic Risk and Aggregate Saving," Quarterly Journal of Economics 109, 659-684.

[2] Aiyagari, S. R. (1995), "Optimal Capital Income Taxation with Incomplete Markets and Borrowing Constraints," Journal of Political Economy 103, 1158-75.

[3] Angeletos, G. M., and L. E. Calvet (2003), "Idiosyncratic Production Risk, Growth, and the Business Cycle," forthcoming in Journal of Monetary Economics.

[4] Angeletos, G. M., and L. E. Calvet (2004), "Incomplete Market Dynamics in a Neoclassical Production Economy," forthcoming in Journal of Mathematical Economics.

[5] Atkeson, A., V.V. Chari, and P. Kehoe (1999), "Taxing Capital Income: A Bad Idea," Federal Reserve Bank of Minneapolis Quarterly Review 23. 
[6] Banerjee, A., and A. Newman (1993), "Occupational Choice and the Process of Development," Journal of Political Economy 101, 274-298.

[7] Benhabib, J., and R. Farmer (1994), "Indeterminacy and Increasing Returns," Journal of Economic Theory 63, 19-41.

[8] Bernanke, B., and M. Gertler (1989), "Agency Costs, Net Worth, and Business Fluctuations," American Economic Review 79, 14-31.

[9] Bewley, T. (1977), "The Permanent Income Hypothesis: A Theoretical Formulation," Journal of Economic Theory 16, 252-292.

[10] Bitler, M., T. Moskowitz, and A. Vissing-Jørgensen (2005), "Testing Agency Theory with Entrepreneur Effort and Wealth," forthcoming in Journal of Finance.

[11] Buera, F. (2004), “A Dynamic Model of Entrepreneurship with Borrowing Constraints," Northwestern University mimeo.

[12] Caggeti, M., and M. De Nardi (2003), "Entrepreneurship, Frictions, and Wealth," Federal Reserve Bank of Minneapolis, Staff Report 322.

[13] Campbell, J., M. Lettau, B. Malkiel, and Y. Xu (2001), "Have Individual Stocks Become More Volatile? An Empirical Exploration of Idiosyncratic Risk," Journal of Finance 56, 1-43.

[14] Campbell, J., and L. Viceira (2000), Strategic Asset Allocation: Portfolio Choice for LongTerm Investors, Oxford, UK: Oxford University Press.

[15] Carroll, C. (2001), "Portfolios of the Rich," in L. Guiso, M. Haliassos, and T. Jappelli, eds., Household Portfolios, Cambridge, Mass.: MIT Press.

[16] Castañeda, A., J. Diaz-Giménez, and V. Ríos-Rull (2003), "Accounting for the U.S. Earnings and Wealth Inequality," Journal of Political Economy 111, 812-857.

[17] Chamley, C. (1986), "Optimal Taxation of Capital Income in General Equilibrium with Infinite Lives," Econometrica 54, 607-622.

[18] Cooper, R. (1999), Coordination Games: Complementarities and Macroeconomics, Cambridge, UK: Cambridge University Press.

[19] Gentry, W.M., and R.G. Hubbard (2000), "Entrepreneurship and Household Saving," Columbia University mimeo.

[20] Huggett, M. (1993), "The Risk Free Rate in Heterogeneous Agent, Incomplete-Insurance Economies," Journal of Economic Dynamics and Control 17, 953-969. 
[21] Huggett, M. (1997), "The One-Sector Growth Model With Idiosyncratic Shocks," Journal of Monetary Economics 39, 385-403.

[22] Judd, K. (1985), "Redistributive taxation in a simple perfect foresight model," Journal of Public Economics 28, 59-83.

[23] Kiyotaki, N., and J. Moore, "Credit Cycles," Journal of Political Economy 105, 211-248.

[24] Kocherlakota, Narayana (2000), "Creating Business Cycles through Credit Constraints," Federal Reserve Bank of Minneapolis, Quarterly Review 24, 2-10.

[25] Krebs, T. (2003), "Human Capital Risk and Economic Growth," Quarterly Journal of Economics 118, 709-744.

[26] Krusell, P., and A. Smith (1998), "Income and Wealth Heterogeneity in the Macroeconomy," Journal of Political Economy 106, 867-896.

[27] Ljungqvist, L., and T.J. Sargent (2000), Recursive Macroeconomic Theory, Cambridge, Mass.: MIT Press.

[28] Jones, L., R. Manuelli, and E. Stacchetti (2000), "Technology and Policy Shocks in Models of Endogenous Growth," Federal Reserve Bank of Minneapolis, Working Paper 281.

[29] Meh, C., and V. Quadrini (2004), "Uninsurable Investment Risks," Bank of Canada/NYU mimeo.

[30] Merton, R. (1969), "Lifetime Portfolio Selection under Uncertainty: The Continuous-Time Case," Review of Economics and Statistics 51, 247-257.

[31] Moskowitz, T., and A. Vissing-Jørgensen (2002), "The Returns to Entrepreneurial Investment: A Private Equity Premium Puzzle?," American Economic Review 92, 745-778.

[32] Obstfeld, M. (1994), "Risk-Taking, Global Diversification, and Growth," American Economic Review 84, 1310-1329.

[33] Quadrini, V. (1999), "The Importance of Entrepreneurship for Wealth Concentration and Mobility," Review of Income and Wealth 45, 1-19.

[34] Samuelson, P.A. (1969), "Lifetime Portfolio Selection By Dynamic Stochastic Programming," Review of Economics and Statistics 51, 239-246. 